\title{
Optical Fiber Power Meter Calibrations at NIST
}

NIST

Special

Publication

250-54

Igor Vayshenker

Xiaoyu Li

David J. Livigni

Thomas R. Scott

Christopher L. Cromer

$\alpha$

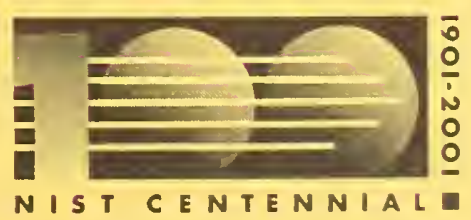


he National Institute of Standards and Technology was established in 1988 by Congress to "assist industry in the development of technology . . . needed to improve product quality, to modernize manufacturing processes, to ensure product reliability . . . and to facilitate rapid commercialization ... of products based on new scientific discoveries."

NIST, originally founded as the National Bureau of Standards in 1901, works to strengthen U.S. industry's competitiveness; advance science and engineering; and improve public health, safety, and the environment. One of the agency's basic functions is to develop, maintain, and retain custody of the national standards of measurement, and provide the means and methods for comparing standards used in science, engineering, manufacturing, commerce, industry, and education with the standards adopted or recognized by the Federal Government.

As an agency of the U.S. Commerce Department's Technology Administration, NIST conducts basic and applied research in the physical sciences and engineering, and develops measurement techniques, test methods, standards, and related services. The Institute does generic and precompetitive work on new and advanced technologies. NIST's research facilities are located at Gaithersburg, MD 20899, and at Boulder, CO 80303. Major technical operating units and their principal activities are listed below. For more information contact the Publications and Program Inquiries Desk, 301-975-3058.

Office of the Director

- National Quality Program

- International and Academic Affairs

\section{Technology Services}

- Standards Services

- Technology Partnerships

- Measurement Services

- Information Services

\section{Advanced Technology Program}

- Economic Assessment

- Information Technology and Applications

- Chemistry and Life Sciences

- Materials and Manufacturing Technology

- Electronics and Photonics Technology

\section{Manufacturing Extension Partnership \\ Program \\ - Regional Programs \\ - National Programs \\ - Program Development}

\section{Electronics and Electrical Engineering Laboratory \\ - Microelectronics \\ - Law Enforcement Standards \\ - Electricity \\ - Semiconductor Electronics \\ - Radio-Frequency Technology \\ - Electromagnetic Technology ${ }^{1}$ \\ - Optoelectronics ${ }^{1}$}

\section{Materials Science and Engineering} Laboratory

- Intelligent Processing of Materials

- Ceramics

- Materials Reliability ${ }^{1}$

- Polymers

- Metallurgy

- NIST Center for Neutron Research
Chemical Science and Technology Laboratory

- Biotechnology

- Physical and Chemical Properties ${ }^{2}$

- Analytical Chemistry

- Process Measurements

- Surface and Microanalysis Science

Physics Laboratory

- Electron and Optical Physics

- Atomic Physics

- Optical Technology

- Ionizing Radiation

- Time and Frequency ${ }^{1}$

- Quantum Physics ${ }^{1}$

Manufacturing Engineering Laboratory

- Precision Engineering

- Automated Production Technology

- Intelligent Systems

- Fabrication Technology

- Manufacturing Systems Integration

\section{Building and Fire Research} Laboratory

- Applied Economics

- Structures

- Building Materials

- Building Environment

- Fire Safety Engineering

- Fire Science

Information Technology Laboratory

- Mathematical and Computational Sciences ${ }^{2}$

- Advanced Network Technologies

- Computer Security

- Information Access and User Interfaces

- High Performance Systems and Services

- Distributed Computing and Information Services

- Software Diagnostics and Conformance Testing

- Statistical Engineering 
NIST Special Publication 250-54

\section{NIST MEASUREMENT SERVICES: Optical Fiber Power Meter Calibrations at NIST}

Igor Vayshenker

Xiaoyu Li

David J. Livigni

Thomas R. Scott

Christopher L. Cromer

Optoelectronics Division

Electronics and Electrical Engineering Laboratory

June 2000

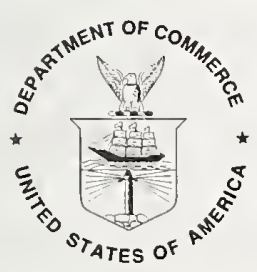

U.S. Department of Commerce

William M. Daley, Secretary

Technology Administration

Dr. Cheryl L. Shavers, Under Secretary of Commerce for Technology

National Institute of Standards and Technology

Raymond G. Kammer, Director 
Certain commercial entities, equipment, or materials may be identified in this document in order to describe an experimental procedure or concept adequately. Such identification is not intended to imply recommendation or endorsement by the National Institute of Standards and Technology, nor is it intended

to imply that the entities, materials, or equipment are necessarily the best available for the purpose.

National Institute of Standards and Technology Special Publication 250-54

Natl. Inst. Stand. Technol. Spec. Publ. 250-54, 41 pages (June 2000)

CODEN: NSPUE2

\section{U.S. GOVERNMENT PRINTING OFFICE}

WASHINGTON: 2000

For sale by the Superintendent of Documents, U.S. Government Printing Office, Washington, DC 20402-9325 


\section{Contents}

1. Introduction 1

2. Laboratory Standard 2

3. Optical Fiber Power Meter Calibrations 6

3.1 Measurement Equation 6

3.2 Calibrations Using Fixed Laser Wavelengths 6

3.2.1 Measurement Assurance Program $\quad 10$

3.3 Calibrations Using Variable Wavelengths From Tunable Laser Diodes 11

3.3.1 Tunable Laser Diode $\quad 11$

3.3.2 Measurement System 13

3.4 Fiber Connector Issues 14

4. Uncertainty Assessment 15

5. Future Work 22

6. References 22

Appendix A. Laser Diode Optical Spectra 24

Appendix B. Measurement Flow Chart 25

Appendix C. Sample of a Calibration Report 26

Appendix D. Wavelength History 32

Appendix E. Sample Results and Shipping Instructions for MAP 33

$\begin{array}{lll}\text { Appendix F. Sample Data Sheet for MAP } & 34\end{array}$

Appendix G. ECPR Linearity Measurements 35

Appendix H. ECPR Uniformity Scans 36 



\title{
Optical Fiber Power Meter Calibrations at NIST
}

Igor Vayshenker, Xiaoyu Li, David J. Livigni, Thomas R. Scott, and Christopher L. Cromer National Institute of Standards and Technology

325 Broadway, Boulder, CO 80303, USA

\begin{abstract}
NIST has established measurement services for the calibration of optical fiber power meters at the three nominal wavelengths of 850,1300 , and $1550 \mathrm{~nm}$ using either collimated beam or optical fiber/connector configurations. This paper describes the measurement standards, techniques, systems, and uncertainties involved with the NIST optical fiber power meter calibration services.
\end{abstract}

Key words: calibration; cryogenic radiometer; measurement service; optical power; optical fiber power meter; spectral responsivity; tunable laser diode; uncertainty; uniformity.

\section{Introduction}

The optical fiber power meter (OFPM) is perhaps the most common type of test equipment used to support the development and implementation of optical fiber systems. To address the inherent metrology requirements, NIST has developed and implemented measurement services to help characterize these instruments [1]. These measurement services consist primarily of absolute laser power calibrations using either collimated beam or optical fiber/connector configurations. In addition, NIST provides measurements of uniformity, nonlinearity, spectral responsivity (based both on tunable lasers and broadband incoherent light sources) for OFPMs. Calibrations are available at the three principal wavelength regions used by the optical fiber telecommunications industry, 850, 1300, and $1550 \mathrm{~nm}$ and, consequently, our measurement services are based primarily on these wavelengths. Other optical power meter users (e.g., compact-disc player manufacturers, users of erbium-doped fiber amplifiers) are additionally interested in wavelengths of 670,780 , and $980 \mathrm{~nm}$. We have also incorporated these wavelengths into our absolute laser power calibration program.

Most OFPMs are based on photodiode sensors made of either silicon ( $\mathrm{Si}$ ), germanium (Ge), or indium gallium arsenide (InGaAs) and, thus, the accurate calibration of these devices must accommodate the inherent characteristics of these devices (e.g., output sensitivity to both spectral and spatial profile of the incident electromagnetic radiation). The electromagnetic radiation is typically provided by laser diodes operating in single-mode or multimode configurations. Unlike solid-state or gas lasers, which operate at well defined wavelengths, diode lasers (due to the manufacturing process) do not operate at a specific wavelength (or center wavelength, for multimode lasers) but typically emit radiation that is within $\pm 10 \mathrm{~nm}$ of some desired value. Factors such as temperature variation can also change the wavelength profile. Consequently, 
detectors which are spectrally sensitive can produce different outputs when exposed to equal powers from different diode lasers or even the same laser under different operational conditions. Naturally, for measurements of high accuracy, both the spectral responsivity of the detector and the spectral pattern of the radiation emitted by the laser diode should be measured.

As shown in NIST studies [2-4], OFPMs can exhibit significant errors when measuring absolute power of radiation delivered through connected fibers. This effect is predominantly due to the reflection of radiation from the diode/window surface back onto the fiber/connector assembly and then reflected back onto the detector. This reflected energy causes the optical power meter to read higher than it would for a collimated beam equal in power. The magnitude of this effect is a function of both wavelength and connector type, and, as a result, the optical power meter should be calibrated with the same fiber and connector with which it is to be used.

NIST optical-power measurement traceability is to the Laser Optimized Cryogenic Radiometer (LOCR) [5-8] based on the electrical substitution method. The laboratory standard is an electrically calibrated pyroelectric radiometer (ECPR) which is then used for the OFPM calibration services. The ECPR has a thermal detector which has a black, highly absorbent coating and has, accordingly, an output that is spectrally insensitive over the wavelength regions of interest for OFPM calibrations. The low-reflectance surface of the ECPR allows it to be used for both collimated beam and optical fiber/connector measurements. The ECPR is used with a measurement system composed of laser diodes, fibers, connectors, fiber splitters, monitors, and lenses to calibrate OFPMs. This measurement system can accommodate most commonly used connector and fiber types.

The following sections of this paper will provide more detailed discussions of the measurement systems presently used in the OFPM calibrations at NIST. Some aspects of these measurement systems and measurement techniques are continually being improved and/or modified to accommodate changing measurement requirements, e.g., adding different laser diodes, improving the transfer standards and calibration software, etc.

\section{Laboratory Standard}

In this section we describe the laboratory standard which is used for OFPM calibrations. The laboratory standard for the NIST optical fiber power measurements is a commercially available, electrically calibrated pyroelectric radiometer which is calibrated optically against the LOCR. The ECPR pyroelectric sensor is made of lithium tantalate that is covered with a gold-black coating on one side. The gold-black coating (approximately $1 \mu \mathrm{m}$ thick) has been evaporated and then deposited under specific temperature and pressure conditions onto the lithium tantalate surface [9]. When deposited in this manner, the gold forms small, interwoven strands which act to trap incident light and, thus, make the gold surface appear black. Gold black is approximately $99 \%$ absorbent $[10]$ in the visible and near-infrared regions. 
Pyroelectric sensors produce an electrical voltage proportional to instantaneous temperature changes [9] and, as a result, the laser energy incident onto the detector must be modulated in order to use this type of detector to measure $\mathrm{CW}$ radiation. The particular detector we use has a chopper wheel which is placed in front of the pyroelectric sensor and is used to 'chop' the beam into pulses at a rate of $15 \mathrm{~Hz}$. Because pyroelectric materials are also piezoelectric, vibration sources must be minimized.

The ECPR is frequently used as a laboratory standard in many optical fiber power calibration laboratories because (1) it is sensitive to low power radiation, (2) it is relatively spectrally flat, and (3) it has a low surface reflectance in the $600 \mathrm{~nm}$ to $1600 \mathrm{~nm}$ wavelength region. This particular type of ECPR is used in the $10 \mu \mathrm{W}$ to $1000 \mu \mathrm{W}$ power range which is the range of primary importance in optical fiber power calibrations. Below $10 \mu \mathrm{W}$ the output becomes too noisy to use reliably and above $1000 \mu \mathrm{W}$ it becomes nonlinear. On the negative side, the ECPR has some disadvantages: (1) nonuniformity of response across the detector surface and (2) fragile nature of the sensor and gold-black coating.

Before the ECPR is used as a laboratory standard, it is first calibrated against the LOCR (direct substitution) at wavelengths of 633,1319 , and $1550 \mathrm{~nm}$ using the system shown in Figure 1. Both the LOCR and ECPR are placed on a motion-controlled stage. Various filters are used to 'clean' the laser beam by removing high-order components. Power is stabilized to achieve high-accuracy measurements. An optical chopper is placed in the beam when using the ECPR; the chopper is removed when using the LOCR. The LOCR was designed to accurately measure the electromagnetic radiation produced by $\mathrm{CW}$ (continuous wave) laser sources in the milliwatt power range. The LOCR was constructed to accommodate the unique characteristics of laser radiation (e.g., nonuniform intensity profiles, temporal and spatial coherence) and can be used over a wide wavelength range. The LOCR's standard uncertainty is $0.02 \%$ at a power of $1 \mathrm{~mW}$. The results of several calibrations are given in Table 1. The details of the ECPR calibration against the LOCR are described in a separate document [11]. To verify the ECPR spectral flatness, we calibrate it at several laser wavelengths against the national primary standard, the LOCR.

The ECPR has an analog voltage output port, but due to the limited resolution of the digital-toanalog converter, this output lacks the accuracy of both the display and the BCD outputs; consequently, to obtain the best ECPR measurement results, either the display reading or the BCD output can be used. For the NIST ECPR calibration, the BCD output is used and is sent to a BCD-to-analog voltage converter. The analog voltage from the converter is then measured with a digital voltmeter. 


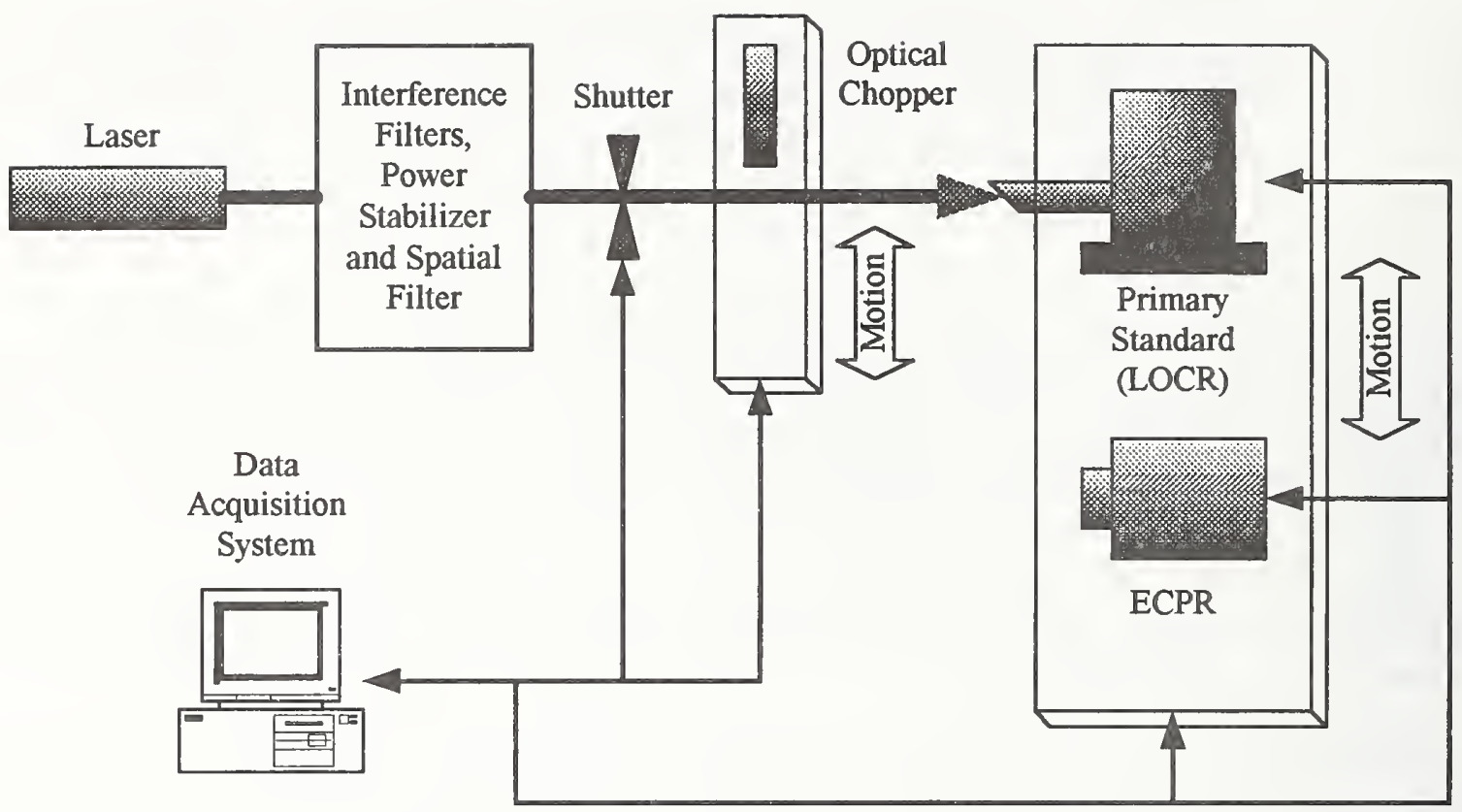

Figure 1. Measurement configuration for ECPR calibration.

Table 1. Calibration factors for ECPR\#618 referenced to LOCR.

\begin{tabular}{cccc}
\hline Date & $\begin{array}{c}\text { Source wavel. } \\
(\mathrm{nm})\end{array}$ & $\begin{array}{c}\text { Calibration } \\
\text { factor }\end{array}$ & $\begin{array}{c}\text { Standard combined } \\
\text { uncertainty } / \%\end{array}$ \\
\hline $11 / 98$ & 633 & 0.9978 & 0.16 \\
$11 / 98$ & 1319 & 0.9945 & 0.16 \\
$11 / 98$ & 1550 & 0.9946 & 0.16 \\
\hline
\end{tabular}

One of the major error sources for the ECPR is the variation of response of the detector for radiation (at constant power) striking different spots of the detector surface. Figure 2 shows a contour map, generated from a spatial uniformity scan that is performed on a NIST ECPR using a beam $2.0 \mathrm{~mm}\left( \pm 0.1 \mathrm{~mm}\right.$ ) in diameter (at $1 / \mathrm{e}^{2}$ intensity points) at a wavelength of $1557 \mathrm{~nm}$ and using $0.2 \mathrm{~mm}$ beam steps. This scan was accomplished using a uniformity measurement system, designed and developed at NIST for characterizing spatial response of optical detectors [12]. 


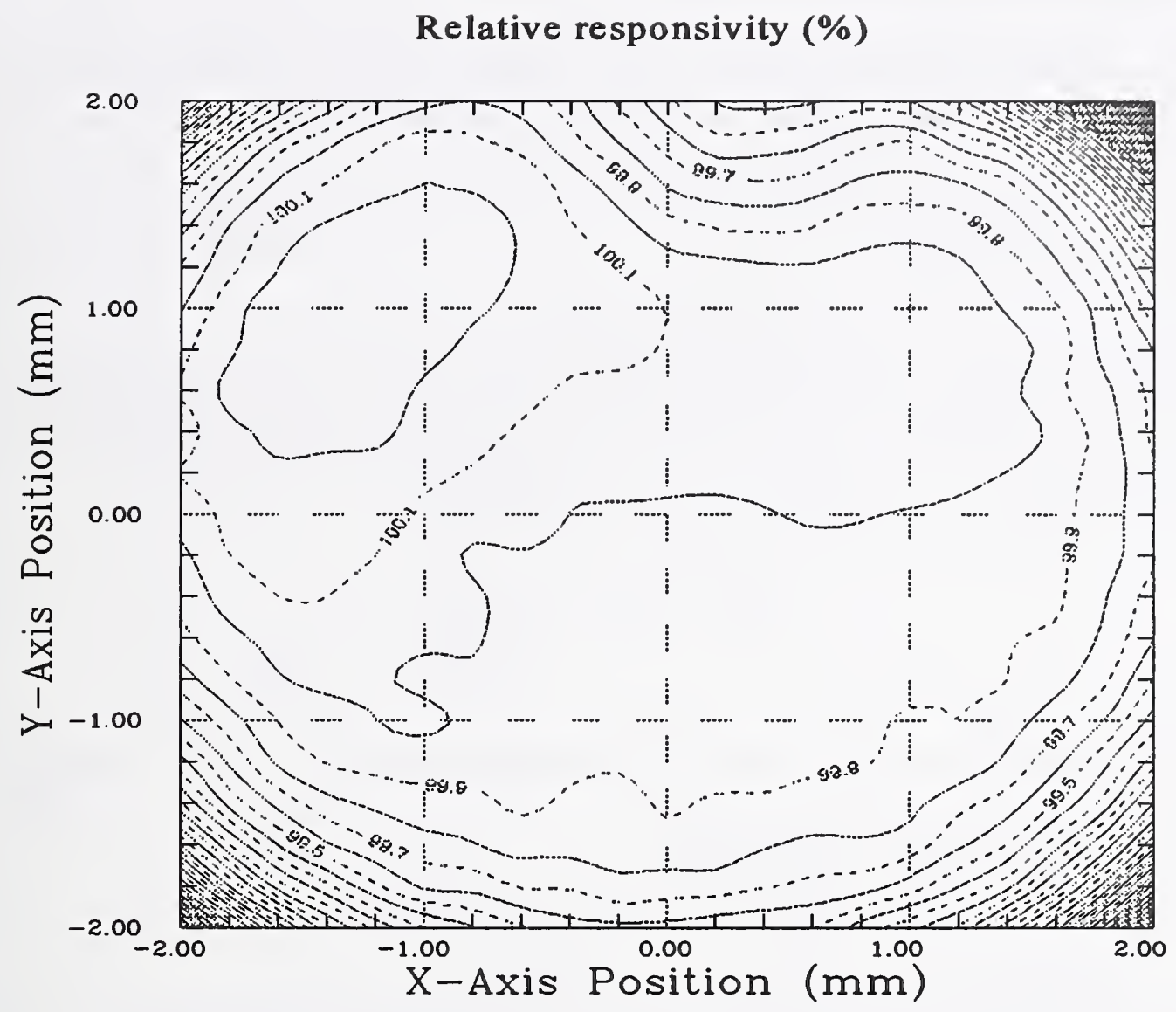

Figure 2. Contour map of the entire dataset, $0.1 \%$ contour line spacing.

The uncertainty due to the nonuniformity of the ECPR sensor can be minimized by always using approximately the same size beam for both the LOCR measurements and for the optical power meter calibration measurements. Also, the laser beam is always centered on the sensor surface and the chopper wheel aperture. To assure that a beam of a similar size (during collimated beam measurements) is always used, we employ a laser beam-profile instrument to measure beam size at the detector location.

The quality-assurance procedure for checking the ECPR before a routine calibration is described in Section 3.2. 


\section{Optical Fiber Power Meter Calibrations}

In this section we describe the measurement equation and the OFPM measurement. We also discuss Measurement Assurance Program (MAP) comparisons of OFPMs.

\subsection{Measurement Equation}

Upon completion of the OFPM calibration, the customer is given a calibration report that lists the resulting calibration factor(s). The calibration factor is obtained by dividing device under test (DUT) net display reading by the incident power. Thus, if the display readings of the DUT are divided by the calibration factor, then, on the average, the resulting values will agree with the NIST national standards. The calibration factor, $\mathrm{F}_{\mathrm{c}}$ is given below:

$$
\mathrm{F}_{\mathrm{c}}=\left(\mathrm{P}_{\mathrm{DUT}} * \mathrm{~V}_{1}\right) /\left(\mathrm{P}_{\mathrm{s}} * \mathrm{~V}_{2}\right) \text {, }
$$

where $P_{D U T}$ is the test power meter reading in units of optical power $(\mu \mathrm{W})$, voltage or current, $P_{s}$ is the ECPR reading in units of $\mu \mathrm{W}$,

$\mathrm{V}_{1}$ is the monitor reading in units of $\mathrm{V}$ with the ECPR in place, $\mathrm{V}_{2}$ is the monitor reading in units of $\mathrm{V}$ with the DUT in place.

Each of the variables in the eq (1) represents a signal with a background reading subtracted. The calibration factor in this paper is the inverse of the correction factor described in reference [13]. Also, the correction factor obtained from our nonlinearity measurements [14] is used to 'correct' a calibration factor determined at a power of $100 \mu \mathrm{W}$.

\subsection{Calibrations Using Fixed Laser Wavelengths}

Figure 3 shows the measurement system configuration used for collimated beam and optical fiber/connector measurements during the calibration of OFPMs. The ECPR is used for these calibrations. The system contains several laser source plates, a connector converter stage (for connectorized measurements), lens assembly (for collimated beam measurements), and a positioning stage for comparing the ECPR and the test meter being calibrated.

An enlarged view of a laser source plate is shown in Figure 4. All system optical fibers are singlemode, whereas the customer's fiber may be either single-mode or multimode. Each laser source plate contains a laser diode whose output is transmitted through a fiber to a fiber splitter from which about $1 \%$ of the energy travels through a fiber to a monitor detector. The remaining $99 \%$ of the energy is transmitted through another fiber to the meter being calibrated. Loose fibers throughout the system are wrapped on spools $5 \mathrm{~cm}$ in diameter to minimize transient microbend 
losses. Also, in this regard, all fibers are securely fixed so that they cannot move during the measurements. All the lasers (except for $1550 \mathrm{~nm}$ ) are of Fabry-Perot types and have several longitudinal (spectral) modes (see Appendix A). The coherence length of each of these lasers is approximately a few centimeters. The $1550 \mathrm{~nm}$ laser is a distributed feedback (DFB) laser with a coherence length of a few hundred meters. The lasers' wavelengths are checked periodically (twice a year). Some of the lasers have been used for over 10 years and have demonstrated high stability over that period.

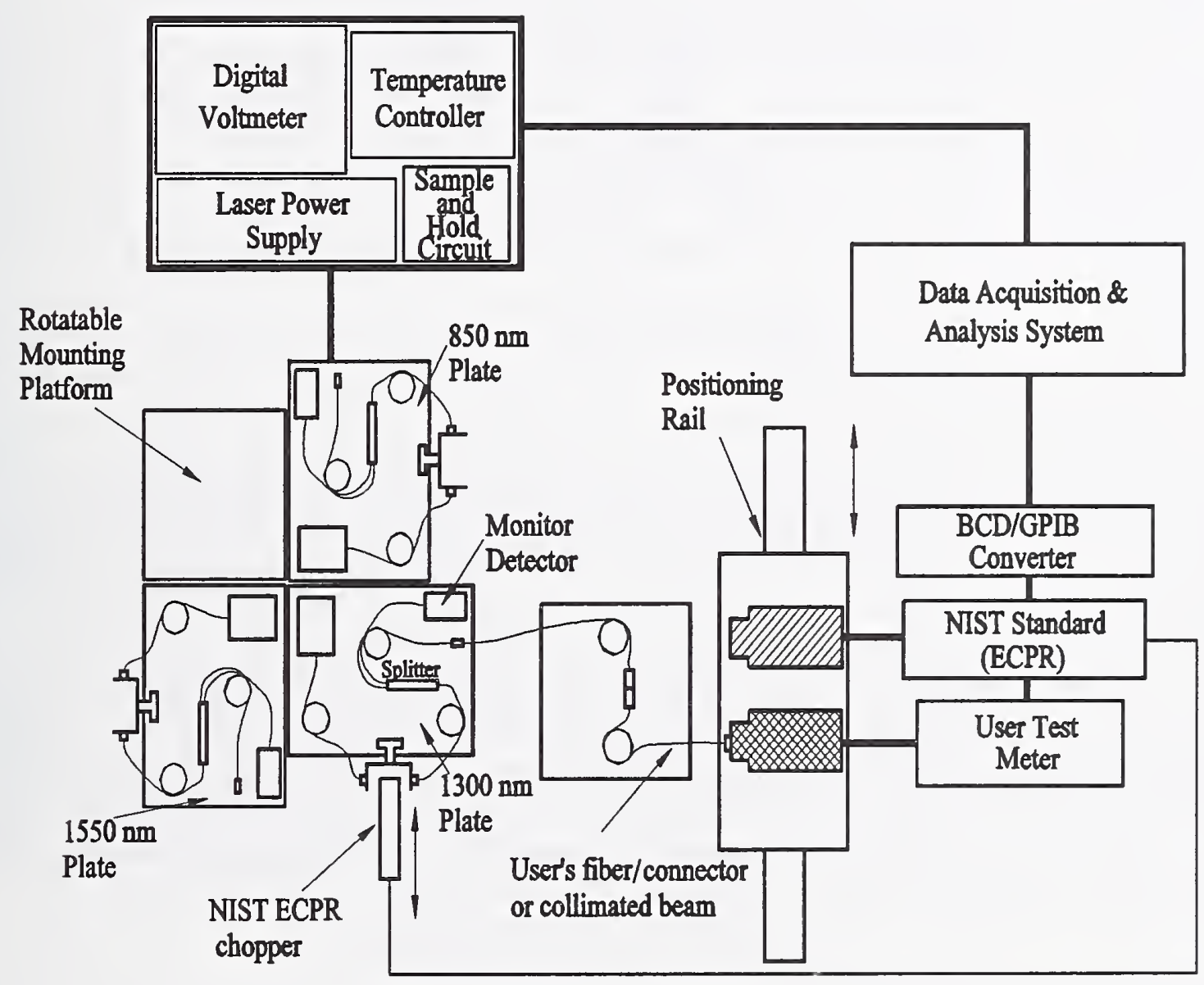

Figure 3. Measurement system. 


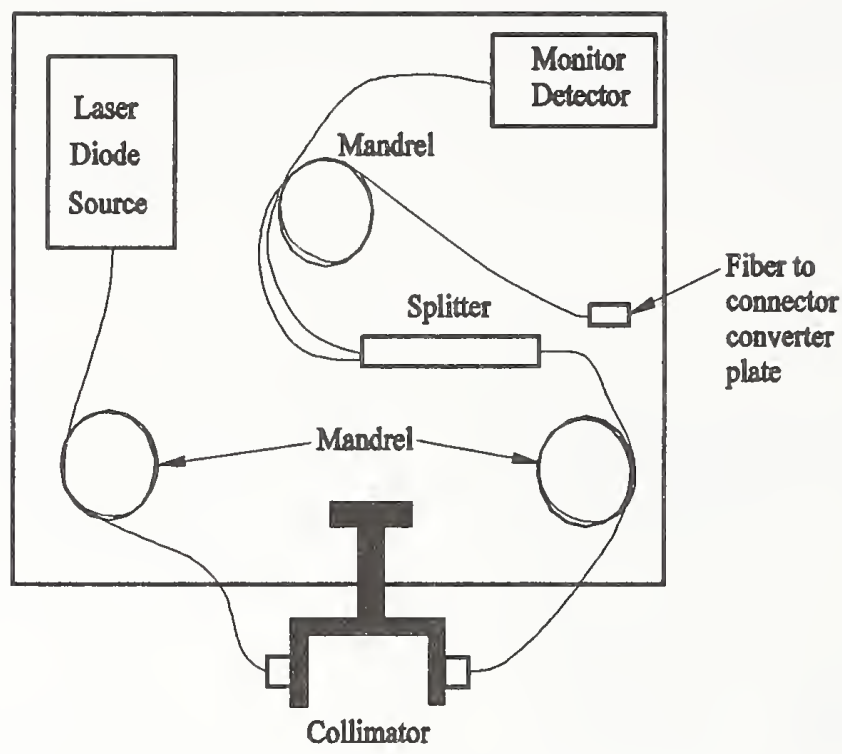

Figure 4. Laser source plate.

As shown in Figure 4 (as well as in Figure 3) a U-shaped collimator fixture is positioned in the propagation path following each diode laser. This fixture contains two lenses that provide a collimated beam for the ECPR chopper wheel to access. When the chopper wheel is inserted into the space provided by this fixture, a chopped beam is then incident on the detectors (i.e., the monitor and the ECPR). The same chopper is used when the ECPR is calibrated against the LOCR. A 'sample-and-hold' current-to-voltage converter is used to monitor the output, and provide an equivalency between powers in CW and chopped beams (the difference between $\mathrm{CW}$ and chopped signals contributes to the uncertainty of a measurement). This converter utilizes a capacitor that stores the peak voltage reading from the chopped signal until the digital voltmeter takes a reading. Each time the ECPR is used for measurements in this system, the chopper wheel is inserted into the collimator fixture opening and is removed when not using the ECPR. The misalignment of the chopper is included in the uncertainty calculation.

For collimated beam measurements, a lens at the end of the fiber path provides a collimated beam to the ECPR and test meter. Note: when using the collimated beam, the calibration factor may vary if the power meter under test has nonuniform spatial responsivity and/or a window that exhibits transmittance variations from coherent interference of multiple reflections. These effects may increase the measurement variation that depends on specific properties of the meter under test. For connectorized measurements, the customer's fiber is connected to the measurement system, which accepts a popular FC/PC (physical contact) optical fiber connector. If the customer's fiber connector is different from FC/PC type, we use a hybrid jumper cable. 
The first step in a calibration measurement is the determination of power in either the collimated beam or from the end of a fiber, whichever is appropriate for a particular situation. For this measurement, either the ECPR is placed in the path of the collimated beam or else the customer's fiber is connected to the ECPR using appropriate adapters. In either case, both the ECPR readings and the monitor detector voltages, $V_{1}$ in eq (1) are recorded. Twenty pairs of measurements are taken over $30 \mathrm{~s}$ (we wait $30 \mathrm{~s}$ before taking the measurements for the ECPR readings to stabilize). Then the ECPR is moved and replaced by the test meter. For connectorized fiber measurements, the fiber connector is moved from the ECPR to the test meter. The test meter readings and the monitor detector voltages, $V_{2}$ in eq (1) are then recorded. Ten or twenty pairs of measurements are taken. Finally, the ECPR is placed back into the beam path (or reconnected to the fiber), and, again, the ECPR and monitor detector readings are recorded. Twenty pairs of measurements are taken. The flow chart of the measurement is shown in Appendix B. The absolute power incident onto the test meter is established by the average ECPR power readings. Power changes (e.g., due to diode laser instability) are taken into account by the monitor detector readings. Thus, this method relies on the short-term stability of the power splitting between the monitor and a customer's fiber, not on its actual value. The 'before' and 'after' ECPR/monitor detector measurements help confirm the stability of power splitting. If the ratio change exceeds a threshold of $0.25 \%$, then the measurements are repeated since it indicates something in the system has not stabilized. This difference is used to calculate the uncertainty of the calibrations. To check the performance of the sample-and-hold circuit and the stability of the laser sources, two measurements are taken, with and without the chopper. If the difference of these two signals exceeds a threshold of $0.25 \%$, then the operator will redo the measurements. This difference is found for a quality-control check only and is not used for the uncertainty calculations. Usually, six runs are performed on a test meter; for quality control two sets of three runs are performed on different days.

We provide quality assurance for the laboratory standard by using a check standard. Before each routine calibration, the check standard (a dedicated power meter, e.g., HP 8152A with a Ge sensor 81521B \#155) is placed in the measurement system shown in Figure 3 . The calibration is performed with a dedicated fiber and the results are stored in a history file. The calibration factor of each particular run is compared with the value obtained in the past. Table 2 shows the results of measurements performed on the NIST check standard.

A sample copy of a calibration report is provided in Appendix C. 
Table 2. Calibration factors for check standard at $1307 \mathrm{~nm}$.

\begin{tabular}{cc}
\hline Date & $\begin{array}{c}\text { Calibration factor } \\
\text { (reading/ } \mu \mathrm{W} \text { ) }\end{array}$ \\
\hline $06-12-1998$ & 1.002 \\
$06-15-1998$ & 1.001 \\
$07-01-1998$ & 1.000 \\
$08-18-1998$ & 1.002 \\
$08-19-1998$ & 1.000 \\
$08-25-1998$ & 1.001 \\
$09-23-1998$ & 1.001 \\
$10-05-1998$ & 1.000 \\
$12-08-1998$ & 1.002 \\
$01-05-1999$ & 1.003 \\
Average & 1.001 \\
St. dev. (\%) & 0.09 \\
\hline
\end{tabular}

Because of spectral-sensitivity issues regarding diode detectors, we must know the center wavelengths of the laser sources for the measurement system. Since the values of center wavelengths have been historically very stable, we periodically (usually twice a year) measure them using a commercial Optical Spectrum Analyzer (OSA). Before the measurements begin, the OSA is warmed up for at least an hour and is calibrated using He-Ne gas lasers that emit radiation at well-defined wavelengths in the $633 \mathrm{~nm}$ and $1523 \mathrm{~nm}$ regions. The history file of the measurements can be found in Appendix D.

\subsubsection{Measurement Assurance Program}

NIST maintains a set of calibrated transfer standards which are available for Measurement Assurance Program (MAP) comparisons of OFPMs. These transfer standards are calibrated using the OFPM calibration system discussed in section 3.2. First, NIST calibrates an appropriate transfer standard using the MAP participant's fiber cable (if applicable), then the meter and the fiber cable are sent to the MAP participant, who compares the NIST transfer standard to his/her laboratory standard. Shipping instructions are included with the meter (see Appendix E). The participant fills out a sample data sheet with his/her measurements, and sends the meter back to 
NIST with the data sheet (see Appendix F). The results of the two sets of NIST measurements are averaged. Then, participant's results are compared to the NIST average. If the difference between two sets of data is larger than the uncertainty of the measurement (approximately $0.5 \%$ ), the measurements are repeated. The MAP Calibration Report then summarizes the results of this comparison including an assessment of the associated uncertainties.

\subsection{Calibrations Using Variable Wavelengths from Tunable Laser Diodes}

NIST provides services for OFPM calibrations at fixed wavelengths using both collimated beam and fiber/connector configurations. However, most users have laser sources whose center wavelengths differ from those used by NIST. To apply NIST's calibration results to the test meter, the meter user must know both the spectral responsivity of the detector and the source wavelength. If the user's source wavelength is different from the wavelength used by NIST during the calibration, the calibration results must be adjusted appropriately. Therefore, it is important to either calibrate the OFPM at the user's laser source wavelength, or provide the user with a spectral responsivity information for the detector used in the OFPM [15].

In this section, we describe a measurement system developed by NIST to calibrate OFPMs at adjustable wavelengths using either collimated-beam or connectorized-fiber configurations. This calibration system uses power-stabilized tunable laser diodes which operate in the three fiber optics windows of $850( \pm 15) \mathrm{nm}, 1300( \pm 30) \mathrm{nm}$, and $1550( \pm 30) \mathrm{nm}$. The lasers include optical isolators to decrease feed back reflections and improve stability (see Figure 5). This system is similar to the system described in Section 3.1.

\subsubsection{Tunable Laser Diode}

To minimize potential measurement errors associated with source wavelength and detector spectral responsivity, we have installed tunable laser sources in the measurement system. The gain medium of the tunable laser is a conventional laser diode but the internal Fabry-Perot resonator is disabled by an antireflection coating on one of the facets. An external cavity is created by adding an external diffraction grating that acts both as a mirror and a wavelengthselective element.

The output power, single-mode operation, and wavelength stability depend strongly on temperature stability. Collimating lenses, shown in Figure 5, collect the divergent laser beam. Since the beam diverges as much as $45^{\circ}$, the lenses must have a numerical aperture (NA) of 0.4 and have surfaces whose wavefront aberrations are less than $\lambda / 4$, where $\lambda$ is the wavelength of the laser radiation.

The lasers use optical isolators to decrease backreflections, which deteriorate the laser power stability. We have also added a radio-frequency source $(10 \mu \mathrm{W}$ in power and $10 \mathrm{MHz}$ in frequency) to the DC drive current to decrease source coherence and further reduce effects of backreflection. 


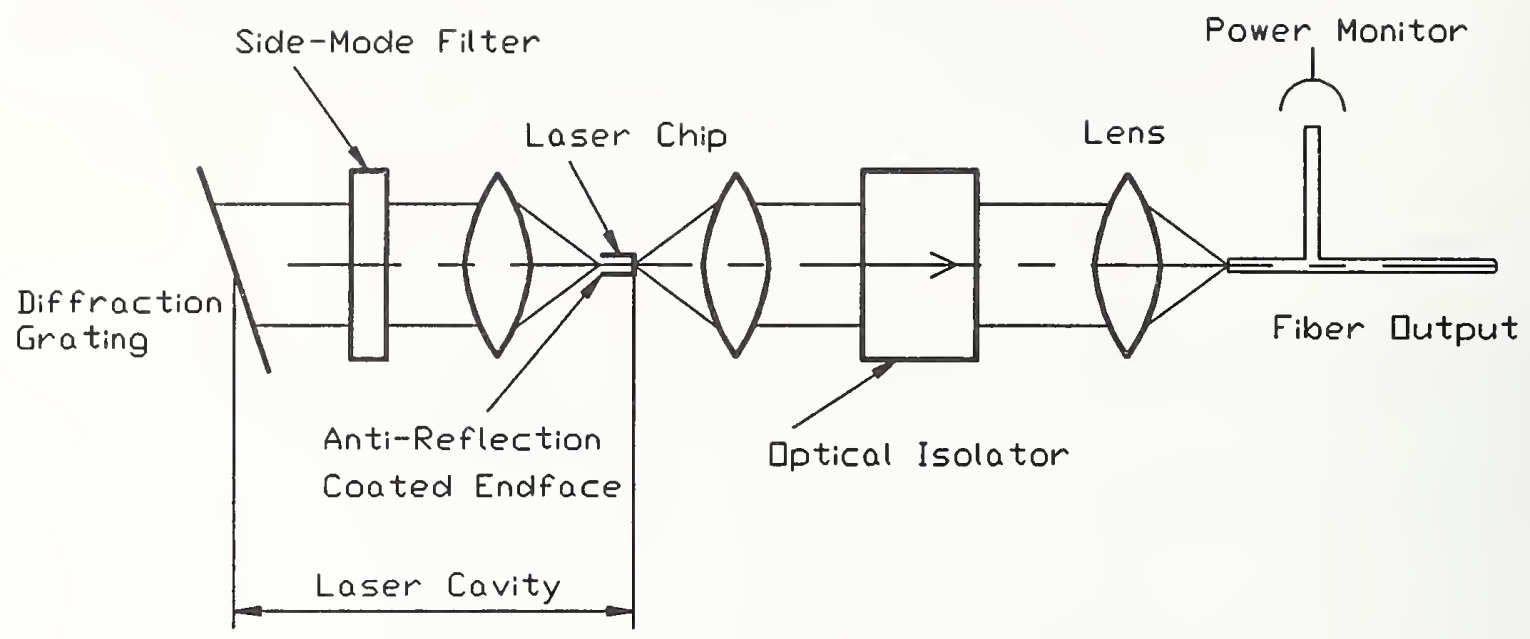

Figure 5. Diagram of tunable laser with an external cavity.

Figure 6 depicts the optical spectra of our $1300 \mathrm{~nm}$ tunable laser diode at three selected settings. The two extreme spectrum lines correspond to two extreme wavelengths that the laser is capable of producing.

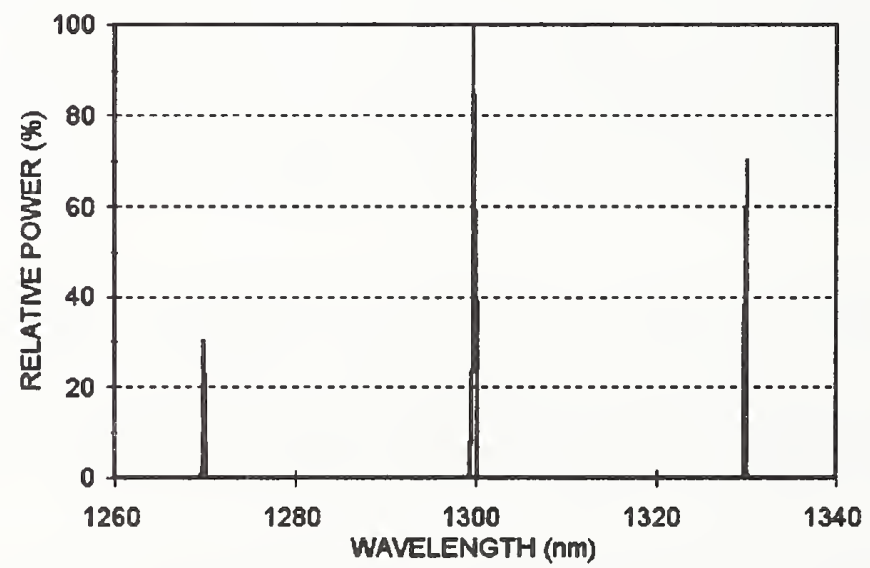

Figure 6. Spectra of $1300 \mathrm{~nm}$ tunable laser diode at three different grating settings. 


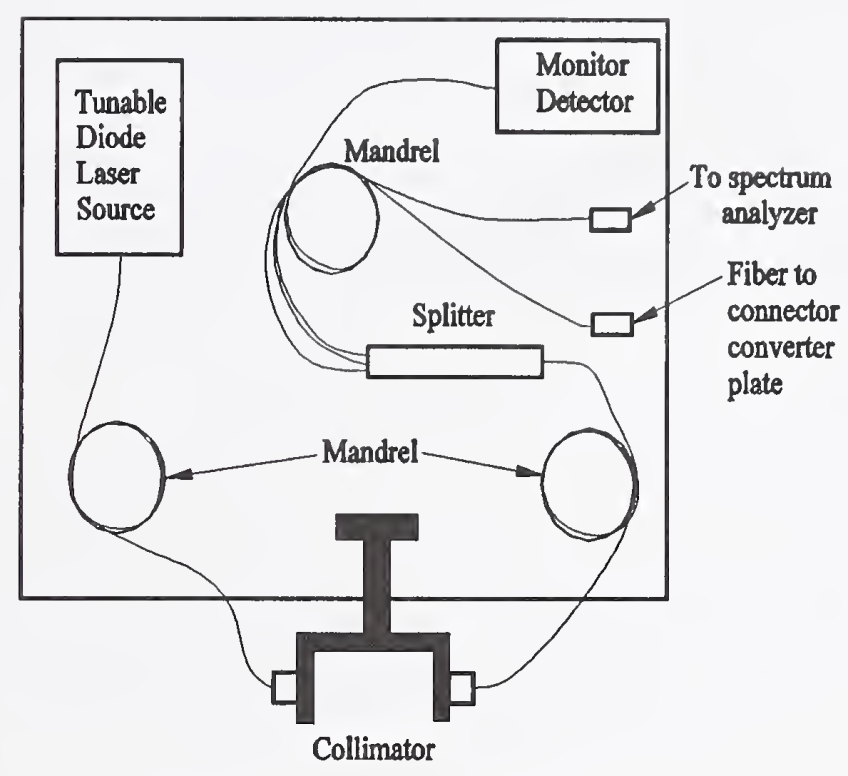

Figure 7. Tunable laser diode stage.

\subsubsection{Measurement System}

Since this system is similar to the measurement system that uses fixed-wavelength laser diodes, we will not describe this system in detail (see Section 3.1 and Figure 3). An enlarged view of a laser source plate is shown in Figure 7. All the optical fibers in the system are single-mode. Each plate contains a laser diode whose output is transmitted to a fiber splitter from which about $5 \%$ of the power is diverted to a monitor and about $1 \%$ of the power to the calibrated OSA.

The remaining power is transmitted through a fiber to the meter being calibrated. All fibers are securely fixed so that they will not move during the measurements. A U-shaped collimator is positioned in the propagation path following each diode laser. This collimator contains two lenses, which provide a collimated beam for the ECPR chopper wheel. When the chopper wheel is inserted into the space provided by this fixture, a chopped beam is then incident onto the detectors (the monitor and the ECPR). To illustrate its capabilities, Figure 8 depicts measured responsivity of a typical germanium detector in the $1550 \mathrm{~nm}$ region using the NIST tunable laser system. 


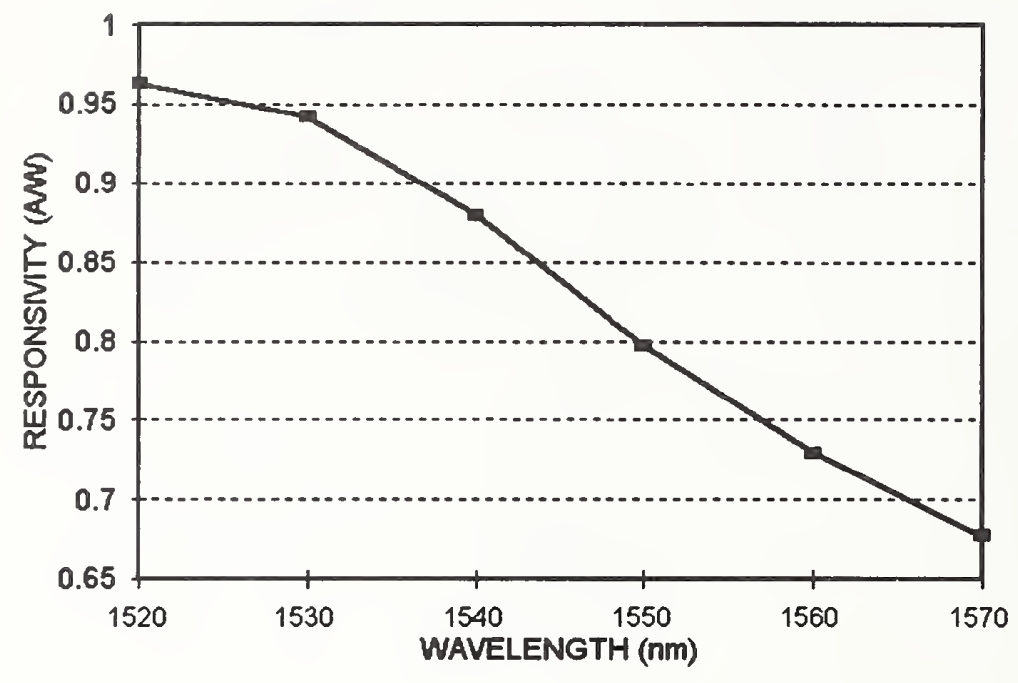

Figure 8. Sample Ge detector responsivity curve using $1550 \mathrm{~nm}$ tunable laser diode.

\subsection{Fiber Connector Issues}

In several optical fiber connector studies [2-4], we showed that the OFPM responsivity can vary dramatically when using various types of connectors or even connectors of the same type but from different vendors. We investigated the magnitude of this connector-induced variation by calibrating several types of OFPMs at wavelengths of 850,1310 , and $1550 \mathrm{~nm}$. In these measurements we varied the connector type and connector vendor, and observed the resulting offsets in calibration results.

When optical fiber power is measured, radiation is transmitted to an OFPM through a fiber attached to a detector by a fiber connector and adapter. The proximity of a fiber connector to the detector and its associated window provide an opportunity for reflections to introduce offsets in the power readings. Even though the measurements using a fiber connector are generally repeatable, changing connectors can skew the measurements results. We selected six common connector types (FC/PC, FC/APC, ST, biconic, SC, and SMA) from four vendors chosen randomly. Calibrations were performed on four types of power meters and at wavelengths of 850,1310 , and $1550 \mathrm{~nm}$.

We found significant measurement offsets resulting from the use of various connectors and a variability within a single connector type obtained from different vendors. Thus, possible errors could likely occur when changing types of connectors or connector vendors on fibers connected to OFPMs. For accurate calibration measurements, meter owners should be aware of the 
connector effects. A laboratory standard such as a thermal device, whose output is insensitive to the connector types, is a useful tool when determining effects due to various connectors. The connector adapter used with the connector is an integral part of the measurement.

The magnitude of the connector-induced offset is wavelength-dependent. The offset is small if a connector has low reflectivity or if the power meter sensor is angled. Also, antireflection coatings can help minimize this effect. It is very important to calibrate an OFPM with the same type of connector used in the actual measurement.

\section{Uncertainty Assessment}

In this section we will assess the uncertainty for the optical fiber power measurement system. The uncertainty estimates for the NIST optical fiber power measurements are described and combined using the referenced guidelines [16]. To establish the uncertainty limits, the uncertainty sources are separated into Type A, whose magnitudes are obtained statistically from a series of measurements, and Type B, whose magnitudes are determined by subjective judgement.

The Type A uncertainty components are assumed to be independent and, consequently, the standard deviation, $S_{r}$, for each component is

$$
S_{r}=\sqrt{\frac{\sum_{i} x_{i}^{2}-\frac{\left(\sum_{i} x_{i}\right)^{2}}{N}}{N-1}},
$$

where the $\mathrm{x}$ values represent the individual measurements and $\mathrm{N}$ is the number of $\mathrm{x}$ values used for a particular Type A component. The standard deviation of the mean is $S_{r} / N^{1 / 2}$, and the total standard deviation of the mean is $\left[\Sigma\left(\mathrm{S}_{\mathrm{r}}^{2} / \mathrm{N}\right)\right]^{1 / 2}$, where the summation is carried out for all Type $\mathrm{A}$ components.

All the Type B components are assumed to be independent and have rectangular or uniform distributions (that is, each has an equal probability of being within the region, $\pm \delta_{s}$, and zero probability of being outside that region). If the distribution is rectangular, the standard deviation, $\sigma_{8}$, for each Type B component is equal to $\delta_{8} / 3^{1 / 2}$ and the total 'standard deviation' is $\left(\Sigma \sigma_{8}^{2}\right)^{1 / 2}$, where the summation is performed over all Type B components.

The combined uncertainty is determined by combining the Type A and Type B standard deviations in quadrature; the expanded uncertainty is obtained by multiplying this result by a coverage factor of 2 . The expanded uncertainty, $U$, is then 


$$
U=2 \sqrt{\sum_{s} \sigma_{s}^{2}+\sum_{r} \frac{S_{r}^{2}}{N}} .
$$

The number of decimal places used in reporting the mean values of the calibration factor are determined by expressing the expanded NIST uncertainty to two significant digits.

In Tables 5 through 7, we describe the OFPM calibration uncertainty using Type A and Type B components. Items a-f (for Type B components) do not change in the uncertainty assessment, while item $g$ depends on specific calibration conditions.

\section{Type A:}

a. Laser power stability: During the calibration of an OFPM, fluctuations in the splitting ratio of power going to the test detector (or ECPR) and the monitor detector can cause a possible error. Also, since the monitor detector and the ECPR have different time constants, a rapidly fluctuating laser diode source can cause an uncertainty in the system ratio measurement. The power stability uncertainty is estimated by observing the 'before' and 'after' (calibration) ECPR readings relative to the monitor output. The difference is recorded and used for the uncertainty calculation. The laser stability standard uncertainty is equal to the difference in the two system ratios. The standard uncertainty changes for each particular calibration.

b. Repeatability: This is an uncertainty due to the scatter of data points around the measurement average obtained from the series of calibration runs (usually six) on the OFPM being calibrated.

\section{Type B:}

a. Ancillary electronics: This uncertainty is due to the combined effect of possible errors in the electronic equipment used in the electrical and laser measurements (the standard uncertainty is $0.01 \%$ ), and a misalignment of the ECPR chopper (the standard uncertainty is $0.04 \%$ ). The values for standard uncertainties are obtained from reference [9] and manufacturers' manuals [1718]. These values are listed in Tables 3 through 5. The combined standard uncertainty is equal to $0.04 \%$.

b. LOCR: This uncertainty consists of two primary components: window transmittance and cavity absorptivity. The window transmittance is measured at several location on the window before and after the calibration. The cavity absorptivity uncertainty is due to radiation which scatters or reflects from the LOCR and, consequently, does not contribute to heating the cavity. The cavity is constructed to minimize this effect as well. The standard combined uncertainty is equal to $0.02 \%$ as described in reference [11].

c. ECPR linearity: This uncertainty is due to the different powers during the calibration of the ECPR against LOCR and actual calibration of a power meter against the ECPR. The magnitude 
of this uncertainty is based on an evaluation of past results in Appendix $G$ that gives the largest difference in calibration factors between calibrations at 0.5 and $1.0 \mathrm{~mW}$. The difference is 0.06 $\%$. Thus, the standard uncertainty is $0.06 /(2 \sqrt{3})=0.02 \%$.

d. ECPR spectral responsivity: This uncertainty is due to the ECPR being somewhat wavelength sensitive. The ECPR is calibrated against the LOCR at wavelengths of 633,1319 , and $1550 \mathrm{~nm}$, but it is used at other wavelengths: $672,786,852,986,1307$, and $1550 \mathrm{~nm}$. Measurements showed small spectral effects between 1319 and $1550 \mathrm{~nm}$ for the ECPR (see Table 1). The maximum calibration factor difference is $0.33 \%$ between $633 \mathrm{~nm}$ and $1319 \mathrm{~nm}$. We use a linear interpolation for the ECPR calibration factors at $672,786,852$ and $986 \mathrm{~nm}$. The standard uncertainty in this region is $0.33 /(2 \sqrt{3})=0.10 \%$. In the wavelength region between 1319 and $1550 \mathrm{~nm}$, the standard uncertainty is less than $0.01 \%$ (see Table 1 ).

e. ECPR uniformity: In addition to the calibration uncertainties listed above, the ECPR has a nonuniform spatial response that can cause a possible error in measurements. The magnitude of this is estimated by performing spatial uniformity scans (see Appendix $\mathrm{H}$ ). We assume that due to misalignments of a laser beam in the radius of $0.5 \mathrm{~mm}$, the maximum spread is $0.13 \%$. The standard uncertainty is $0.13 /(2 \sqrt{3})=0.04 \%$.

f. Connector: This uncertainty is due to effects caused by a fiber connector on the ECPR. The ECPR is calibrated against the LOCR using a collimated beam, but is used with fiber connectors to calibrate customers' power meters. We compared our ECPR with several pyroelectric trap detectors at various wavelengths using both a collimated beam and a FC/PC fiber connector. Four measurements were performed. The largest difference between the collimated beam and connectorized measurements is $0.34 \%$. The standard uncertainty is $0.34 /(2 \sqrt{3})=0.10 \%$. Note: this approach does not 'protect' from 'the-worst case scenario' - interchanging different types of connectors, power meters and connectors from different manufacturers at random. We assume that the power meter owner utilizes the same fiber cable, connectors and connector adapters used by NIST during the calibration of the power meter.

g. Test meter wavelength effect: This uncertainty is due to the drift in the source wavelength. The magnitude of this effect is proportional to the wavelength uncertainty times the spectral response gradient of the test detector at the wavelength being used. This uncertainty can be quite large if the spectral response curve is changing rapidly (e.g., Ge detectors in the $1550 \mathrm{~nm}$ region). NIST keeps a history file on all OFPM system laser wavelengths. The wavelength uncertainty value for a specific test meter is found by assuming that the standard uncertainty of the OSA is $0.13 \mathrm{~nm}$ including the instrument drift. A typical spectral responsivity curve (see Table 3 ) for the test meter is used. Typical spectral responsivity slopes $(\% / \mathrm{nm})$ are given in Table 3. 
Table 3. Spectral responsivity slope $(\% / \mathrm{nm})$ for $\mathrm{Si}, \mathrm{Ge}$, and $\mathrm{InGaAs}$ detectors.

\begin{tabular}{ccccc}
\hline Diode Type & \multicolumn{4}{c}{ Wavelength (nm) } \\
& $670 \& 780$ & $850 \& 980$ & 1300 & 1550 \\
\hline $\mathrm{Si}$ & 0.31 & 0.14 & $\mathrm{NA}$ & $\mathrm{NA}$ \\
$\mathrm{Ge}$ & $\mathrm{NA}$ & 0.48 & 0.14 & 0.92 \\
$\mathrm{InGaAs}$ & $\mathrm{NA}$ & 0.53 & 0.09 & 0.05 \\
\hline
\end{tabular}

Table 4 gives standard uncertainty values for $\mathrm{Si}, \mathrm{Ge}$, and $\mathrm{InGaAs}$ detectors. We combine the OSA uncertainty with the sources' wavelength drift value from Appendix D. The standard uncertainty due to this wavelength effect is equal to the appropriate value from Table 3 multiplied by the combined uncertainty of the OSA and the source wavelength drift value from Appendix D.

Tables 5 through 7 list typical measurement uncertainties for calibrations of OFPMs which use $\mathrm{Si}$, $\mathrm{Ge}$, and InGaAs detectors, respectively. The exact values of these various components change for the particular measurement conditions at the time of the measurement.

Table 4. Standard uncertainty (\%) for spectral responsivity for $\mathrm{Si}, \mathrm{Ge}$, and $\mathrm{InGaAs}$ detectors.

\begin{tabular}{ccccccc}
\hline Diode Type & \multicolumn{5}{c}{ Wavelength (nm) } \\
& 670 & 780 & 850 & 980 & 1300 & 1550 \\
\hline $\mathrm{Si}$ & 0.05 & 0.10 & 0.04 & 0.02 & NA & NA \\
Ge & NA & NA & 0.13 & 0.06 & 0.03 & 0.15 \\
InGaAs & NA & NA & 0.14 & 0.07 & 0.02 & 0.01 \\
\hline
\end{tabular}


Table 5. Typical measurement uncertainties for a Si detector at $850 \mathrm{~nm}$ * $^{*}$

Source Standard uncertainty (type)

(\%)

Electronics

0.04 (B)

LOCR

$0.02(\mathrm{~B})$

ECPR linearity

$0.02(\mathrm{~B})$

ECPR spectral responsivity

@ 850 nm

$0.10(\mathrm{~B})$

ECPR uniformity

0.04 (B)

Connector**

$0.10(\mathrm{~B})$

Laser power stability

$0.06(\mathrm{~A})$

Test meter spectral responsivity

@ 850 nm

0.04 (B)

Repeatability $(\mathrm{N}=6)$

@ 850 nm

$0.12 / \sqrt{6}(\mathrm{~A})$

Combined uncertainty

@ 850 nm

0.178

Expanded uncertainty $(\mathrm{k}=2)$

(a) $850 \mathrm{~nm}$

0.36

"For other wavelengths, the appropriate test meter spectral responsivity (Table 4) is substituted.

"** For the collimated beam measurements, the connector-related uncertainty is equal to zero. 
Table 6. Typical measurement uncertainties for a Ge detector at $1300 \mathrm{~nm}$. ${ }^{*}$

Source Standard uncertainty (type)

$(\%)$

Electronics

$0.04(\mathrm{~B})$

LOCR

$0.02(B)$

ECPR linearity

$0.02(\mathrm{~B})$

ECPR spectral responsivity

(a) $1300 \mathrm{~nm}$

$0.01(\mathrm{~B})$

ECPR uniformity

$0.04(\mathrm{~B})$

Connector $^{* *}$

$0.10(\mathrm{~B})$

Laser power stability

$0.04(\mathrm{~A})$

Test meter spectral responsivity

(@) $1300 \mathrm{~nm}$

$0.03(\mathrm{~B})$

Repeatability $(\mathrm{N}=6)$

@ $1300 \mathrm{~nm}$

$0.07 / \sqrt{6}(\mathrm{~A})$

Combined uncertainty

@ $1300 \mathrm{~nm}$

0.132

Expanded uncertainty $(\mathrm{k}=2)$

@ $1300 \mathrm{~nm}$

0.26

* For other wavelengths, use appropriate the ECPR spectral responsivity uncertainty (item d, p. 17) and appropriate test meter spectral responsivity (Table 4).

** For the collimated beam measurements, the connector-related uncertainty is equal to zero. 
Table 7. Typical measurement uncertainties for an InGaAs detector at $1550 \mathrm{~nm}^{*}{ }^{*}$

Source Standard uncertainty (type)

(\%)

Electronics

LOCR

$0.02(\mathrm{~B})$

ECPR linearity

$0.02(\mathrm{~B})$

ECPR spectral responsivity

@ $1300 \& 1550 \mathrm{~nm}$

$0.01(\mathrm{~B})$

ECPR uniformity

$0.04(\mathrm{~B})$

Connector**

Laser power stability

$0.06(\mathrm{~A})$

Test meter spectral responsivity

@ $1550 \mathrm{~nm}$

Repeatability $(\mathrm{N}=6)$

@ 1550 nm

$0.22 / \sqrt{6}(\mathrm{~A})$

Combined uncertainty

@ $1550 \mathrm{~nm}$

Expanded uncertainty $(\mathrm{k}=2)$

(a) $1550 \mathrm{~nm}$

0.32

${ }^{*}$ For other wavelengths, use appropriate the ECPR spectral responsivity uncertainty (item d, p. 17) and appropriate test meter spectral responsivity (Table 4).

"* For the collimated beam measurements, the connector-related uncertainty is equal to zero. 


\section{Future Work}

Even though the ECPR is the laboratory standard at this time, improved pyroelectric and quantum detectors are now being developed and may eventually replace the current instrument. The wavelength uncertainty could be decreased by introducing laser-stabilizing Bragg gratings that lock the laser diode output wavelength to the Bragg wavelength of the fiber grating. At the present time, the measurement system can accommodate most commonly used connector types. Because of the constantly changing measurement requirements (new wavelengths, power levels and connector types), we have to upgrade our capabilities from time to time. There is an effort to modernize the existing calibration software as well.

This work was supported in part by the Calibration Coordination Group (CCG) of the Department of Defense and NIST's Calibration Services Development Fund. Kent Rochford, Steven Mechels, and Jack Wang of NIST reviewed the manuscript, John Lehman of NIST provided useful insights on optical fiber power meters' spectral-responsivity measurements and transfer standards; the authors thank them for their valuable comments.

\section{References}

[1] Laser power and energy, in Natl. Inst. Stand. Technol. Spec. Publ. 250, 98-103, 1998.

[2] Gallawa, R. L.; Li, X. Calibration of optical fiber power meters: The effect of connectors. Appl. Opt. 26(7): 1170-1174, April 1, 1987.

[3] Vayshenker, I.; Li, X.; Keenan, D.; Scott, T.R. Errors due to connectors in optical fiber power meters. Natl. Inst. Stand. Technol. Spec. Publ. 905, 49-52, 1996.

[4] Vayshenker, I.; Li, X.; Keenan, D.; Scott, T.R. FO connector types affect power measurements. Test Meas. World, 23-25; February 1997.

[5] Cambridge Research and Instrumentation, Inc., 21 Erie Street, Cambridge, MA 02139.

[6] Foukal, P.V.; Hoyt C.; Kochling H.; Miller P. Cryogenic absolute radiometers as laboratory irradiance standards, remote sensing detectors, and pyroheliometers. Appl. Opt. 29(7): 988$993 ; 1990$.

[7] Johnson, B. C.; Kumar, A.R.; Zhang, Z. M.; Livigni, D.J.; Jones, R.D.; Scott, T. R. Heat transfer analysis and modeling of a cryogenic laser radiometer. J. Thermophys. Heat Trans. 12(4): 575-581, October-December 1998. 
[8] Livigni, D.J.; Cromer, C.L.; Scott, T.R.; Johnson, B.C.; Zhang, Z.M. Thermal characterization of a cryogenic radiometer and comparison with a laser calorimeter. Metrologia 35(6), 819-827; 1998.

[9] Hamilton, C.A.; Day, G.W.; Phelan, R.J. Jr. An electrically calibrated pyroelectric radiometer system. Nat. Bur. Stand.(U.S.) Tech. Note 678; March 1976.

[10] Wolfe, W.L.; Zissis, G.J., eds. The Infrared Handbook. Washington, DC: Environmental Research Inst. of Michigan, 7-79; 1985.

[11] Livigni, D.J. High accuracy laser power calibration service. To be published as Natl. Inst. Stand. Technol. Spec. Publ. 250-55.

[12] Livigni, D.J.; Li, X. Spatial uniformity of optical detector responsivity. Proc., National. Conference of Standards Laboratories Workshop \& Symp., Session 5A, 337-352; JulyAugust 1994.

[13] International Standard: Calibration of fibre optic power meters. CEI/IEC 1315; 1995.

[14] Vayshenker, I.; Yang, S.; Li, X.; Scott, T.R.; Cromer, C.L. Optical fiber power meter nonlinearity calibrations at NIST. To be published as Natl. Inst. Stand. Technol. Spec. Publ. 250-56, 2000.

[15] Vayshenker, I.; Li, X.; Scott, T.R. Optical power meter calibration using tunable laser diodes. Proc., National Conference of Standards Laboratories Workshop \& Symp., Session 5A, 362-372; July-August 1994.

[16] Taylor B.N.; Kuyatt, C.E. Guidelines for evaluating and expressing the uncertainty of NIST measurement results. Natl. Inst. Stand. Technol. Tech. Note 1297; September 1994.

[17] Hewlett-Packard 3457 multimeter operating manual. 1-11; 1986.

[18] Laser Precision Corp. RS-5900 electrically calibrated pyroelectric radiometer instruction manual, 33-34; 1982. 


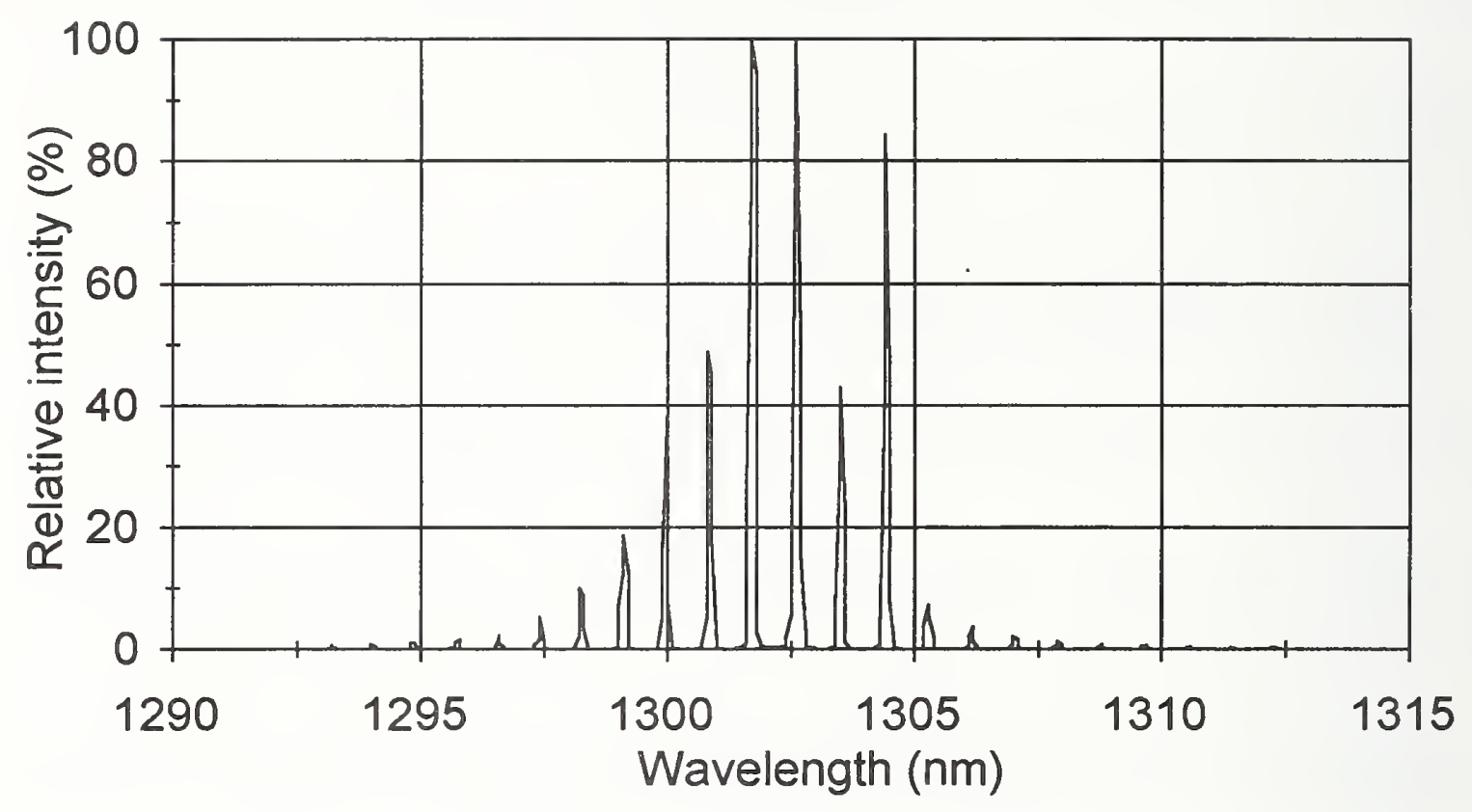

Figure A-1. Optical spectra of a typical laser diode used in the OFPM calibration system. 


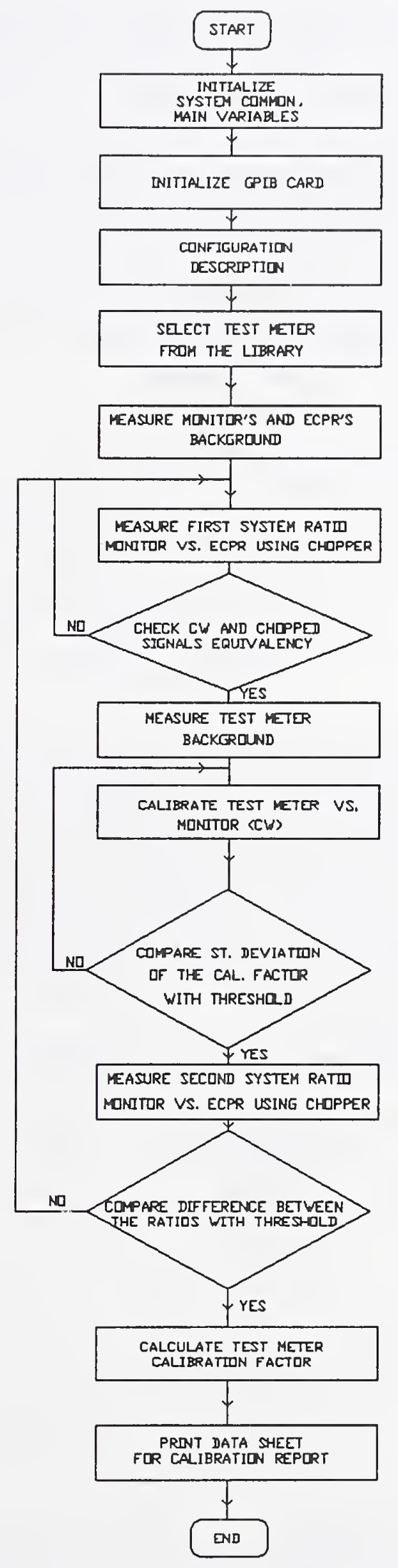




\title{
U.S. DEPARTMENT OF COMMERCE \\ NATIONAL INSTITUTE OF STANDARDS AND TECHNOLOGY \\ ELECTRONICS \& ELECTRICAL ENGINEERING LABORATORY \\ Boulder, Colorado 80303
}

\section{REPORT OF CALIBRATION for}

\author{
OPTICAL POWER METER \\ Meter's Manufacturer \\ Model Number \\ Serial Number \\ with Sensor \\ Model Number and Serial Number \\ Submitted by: \\ Company Name \\ Address
}

\section{Calibration Summary}

The test optical power meter and the associated sensor was calibrated at wavelengths of 851.9, 1307.0, and $1549.6 \mathrm{~nm}$ (with a $0.13 \mathrm{~nm}$ standard uncertainty) by comparing it to a calibrated laboratory standard (see Figure 1). The NIST laboratory standard was an electrically calibrated pyroelectric radiometer (ECPR) which had previously been calibrated against the NIST Laser Optimized Cryogenic Radiometer (LOCR) system. The single-mode fiber with FC/PC connectors was supplied by the test meter owner. Before the measurements began, the instruments were allowed to reach equilibrium with the laboratory environment and the zero setting was adjusted as specified by the manufacturer.

Table 1. Calibration results (Power: $100 \mu \mathrm{W}$ ).

\begin{tabular}{ccccc}
\hline $\begin{array}{c}\text { Detector/ } \\
\text { fiber type }\end{array}$ & $\begin{array}{c}\text { Source } \\
\text { wavelength } \\
(\mathrm{nm})\end{array}$ & $\begin{array}{c}\text { Meter } \\
\text { setting } \\
(\mathrm{nm})\end{array}$ & $\begin{array}{c}\text { Calibration } \\
\text { factor } \\
(\text { reading/ } \mu \mathrm{W})\end{array}$ & $\begin{array}{c}\text { Expanded } \\
\text { uncertainty } \\
(\mathrm{k}=2) \\
(\%)\end{array}$ \\
\hline $\mathrm{Si} / \mathrm{SM}$ & 851.9 & 851.9 & 0.9986 & 0.34 \\
$\mathrm{Ge} / \mathrm{SM}$ & 1307.0 & 1307.0 & 0.9994 & 0.28 \\
$\mathrm{Ge} / \mathrm{SM}$ & 1549.6 & 1549.6 & 0.9989 & 0.41 \\
\hline
\end{tabular}

Folder No. \& NISTID:

Date of Report:

Reference:
$26100 \& 815000$

November 19, 1999

P.O. No. $10000010 / 28 / 99$ 
Meter's Manufacturer

Model Number

Serial Number

with Sensor

Model Number and Serial Number

The laboratory temperature during these measurements was $22^{\circ} \mathrm{C}\left( \pm 2{ }^{\circ} \mathrm{C}\right)$ and the relative humidity was $11 \%( \pm 3.5 \%)$. The wavelength selection was set to the value listed in Table 1 . The test meter calibration factor was obtained by dividing its net display reading by the incident power.

The results of this calibration are summarized in Table 1. If the display readings of the test meter are divided by the calibration factor in Table 1, then, on the average, the resulting values will agree with the NIST national reference standards.

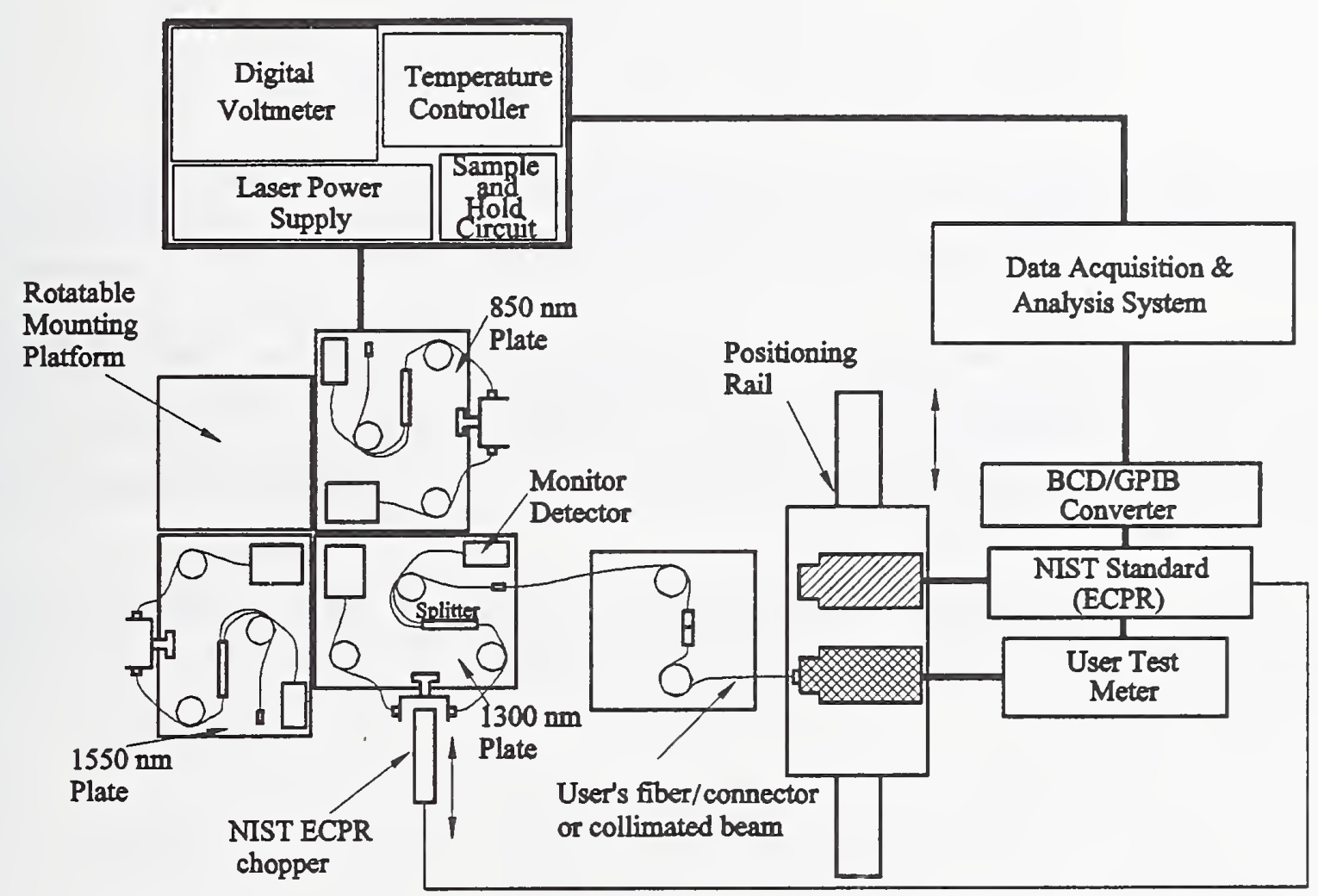

Figure 1. Measurement system.

Folder No. \& NISTID:

Date of Report:

Reference:
$26100 \& 815000$

November 19, 1999

P.O. No. $10000010 / 28 / 99$ 
Meter's Manufacturer

Model Number

Serial Number

with Sensor

Model Number and Serial Number

\section{Uncertainty Assessment}

The uncertainty estimates for the NIST laser energy measurements are described and combined using the referenced guidelines in NIST Technical Note 1297. To establish the uncertainty limits, the uncertainty sources are separated into Type A, whose magnitudes are obtained statistically from a series of measurements and Type $B$, whose magnitudes are determined by subjective judgement.

The Type A uncertainty components are assumed to be independent and, consequently, the standard deviation, $S_{n}$, for each component is

$$
S_{r}=\sqrt{\frac{\sum_{i} x_{i}^{2}-\frac{\left(\sum_{i} x_{i}\right)^{2}}{N}}{N-1}},
$$

where the $x_{i}$ values represent the individual measurements and $N$ is the number of $x_{i}$ values used for a particular Type A component. The standard deviation of the mean is $S_{r} / N^{1 / 2}$, and the total standard deviation of the mean is $\left[\Sigma\left(\mathrm{S}_{\mathrm{r}}{ }^{2} / \mathrm{N}\right)\right]^{1 / 2}$, where the summation is carried out for all Type $A$ components.

All the Type B components are assumed to be independent and have rectangular or uniform distributions (that is, each has an equal probability of being within the region, $\pm \delta_{s}$, and zero probability of being outside that region). If the distribution is rectangular, the standard deviation $\sigma_{3}$, for each Type $B$ component is equal to $\delta_{s} / 3^{1 / 2}$ and the total "standard deviation" is $\left(\Sigma \sigma_{s}{ }^{2}\right)^{1 / 2}$, where the summation is performed over all Type B components.

The combined uncertainty is determined by combining the Type A and Type B standard deviations in quadrature; the expanded uncertainty is obtained by multiplying this result by a factor of 2 . The expanded uncertainty, $U$, is then

$$
U=2 \sqrt{\sum_{s} \sigma_{s}^{2}+\sum_{r} \frac{S_{r}^{2}}{N}} .
$$

The values used to calculate the NIST expanded uncertainty (shown in Table 1) are listed in Tables 2 and 3. The number of decimal places used in reporting the mean values of the calibration factor listed in Table 1 were determined by expressing the expanded NIST uncertainty to two significant digits.

Folder No. \& NISTID:

Date of Report:

Reference:
$26100 \& 815000$

November 19, 1999

P.O. No. $10000010 / 28 / 99$ 
Meter's Manufacturer

Model Number

Serial Number

with Sensor

Model Number and Serial Number

Table 2. NIST measurement uncertainties for Si detector at $850 \mathrm{~nm}$.

\begin{tabular}{lc}
\hline Source & $\begin{array}{c}\text { Standard uncertainty (type) } \\
(\%)\end{array}$ \\
\hline Electronics & $0.04(\mathrm{~B})$ \\
LOCR & $0.02(\mathrm{~B})$ \\
Laboratory standard linearity & $0.02(\mathrm{~B})$ \\
Laboratory standard spectral responsivity & \\
@ $850 \mathrm{~nm}$ & $0.10(\mathrm{~B})$ \\
Laboratory standard uniformity & \\
Connector & $0.04(\mathrm{~B})$ \\
Laser power stability & $0.10(\mathrm{~B})$ \\
Test meter spectral responsivity & $0.06(\mathrm{~A})$ \\
@ $850 \mathrm{~nm}$ & \\
$\begin{array}{l}\text { Repeatability }(\mathrm{N}=6) \\
\text { @ } 850 \mathrm{~nm} \\
\text { Combined uncertainty }\end{array}$ & $0.04(\mathrm{~B})$ \\
@ $850 \mathrm{~nm}$ & \\
$\begin{array}{l}\text { Expanded uncertainty (k=2) } \\
\text { @ } 850 \mathrm{~nm}\end{array}$ & $0.05 / \sqrt{6}(\mathrm{~A})$ \\
\hline
\end{tabular}

Folder No. \& NISTID: 
Meter's Manufacturer

Model Number

Serial Number

with Sensor

Model Number and Serial Number

Table 3. NIST measurement uncertainties for Ge detector at 1300 and $1550 \mathrm{~nm}$.

Source

Standard uncertainty (type)

$(\%)$

Electronics

$0.04(\mathrm{~B})$

LOCR

$0.02(\mathrm{~B})$

Laboratory standard linearity

$0.02(B)$

Laboratory standard spectral responsivity

(@) 1300 and 1550 nm

$0.01(\mathrm{~B})$

Laboratory standard uniformity

$0.04(\mathrm{~B})$

Connector

$0.10(\mathrm{~B})$

Laser power stability

$0.06(\mathrm{~A})$

Test meter spectral responsivity

(@) $1300 \mathrm{~nm}$

$0.03(\mathrm{~B})$

(a) $1550 \mathrm{~nm}$

$0.15(\mathrm{~B})$

Repeatability $(\mathrm{N}=6)$

(a) 1300 nm

$0.07 / \sqrt{6}(\mathrm{~A})$

(@) $1550 \mathrm{~nm}$

$0.12 / \sqrt{6}(\mathrm{~A})$

Combined uncertainty

(@) $1300 \mathrm{~nm}$

0.139

@ $1550 \mathrm{~nm}$

0.206

Expanded uncertainty $(\mathrm{k}=2)$

(a) $1300 \mathrm{~nm}$

0.28

@ 1550 nm

0.41

Folder No. \& NISTID:

Date of Report:

Reference:
$26100 \& 815000$

November 19, 1999

P.O. No. $10000010 / 28 / 99$ 
Meter's Manufacturer

Model Number

Serial Number

with Sensor

Model Number and Serial Number

For the Director,

National Institute of Standards and Technology

Thomas R. Scott, Group Leader Sources and Detectors Group

Optoelectronics Division

Report Reviewed By:

Christopher L. Cromer, Project Leader Sources and Detectors Group Optoelectronics Division

Report Prepared/Calibrated By:

Igor Vayshenker, Electronics Engineer

Sources and Detectors Group

Optoelectronics Division

Folder No. \& NISTID:

Date of Report:

Reference:
$26100 \& 815000$

November 19, 1999

P.O. No. $10000010 / 28 / 99$ 


\section{Appendix D. Wavelength History}

This appendix describes the wavelength (in vacuum) history file for the lasers used in the optical fiber power measurement system. All the measurements were taken with a calibrated optical spectrum analyzer (OSA). Wavelength uncertainty is found by combining the OSA uncertainty with the standard deviation of measured wavelength variation.

Table D-1. Wavelength History File for the OFPM System's Lasers

\begin{tabular}{|c|c|c|c|c|c|c|c|c|}
\hline Date & \multicolumn{8}{|c|}{ Wavelength (nm) } \\
\hline $11 / 92$ & 672.3 & 786.3 & 841.0 & NA & NA & NA & 1306.7 & 1549.7 \\
\hline $05 / 93$ & 672.3 & 785.9 & NA & 852.1 & NA & NA & NA & 1549.6 \\
\hline $02 / 94$ & 672.3 & 785.5 & 840.9 & 852.3 & NA & NA & 1307.2 & 1549.5 \\
\hline $10 / 96$ & 672.3 & 786.2 & 840.7 & 852.1 & NA & NA & 1307.0 & 1549.7 \\
\hline 07/97 & 672.2 & 785.8 & 840.6 & 851.9 & NA & 1304.2 & 1307.1 & 1549.4 \\
\hline $02 / 98$ & 672.1 & 786.1 & 840.4 & 851.6 & NA & 1304.3 & 1306.9 & 1549.6 \\
\hline 08/98 & 672.1 & 785.6 & 840.5 & 851.8 & NA & 1304.3 & 1307.0 & 1549.6 \\
\hline $11 / 98$ & 672.2 & 786.2 & 840.6 & 851.8 & NA & 1304.3 & 1306.8 & 1549.6 \\
\hline 03/99 & 672.3 & 786.1 & 840.6 & 851.7 & 986.0 & NA & 1307.0 & 1549.6 \\
\hline Average (nm) & 672.2 & 786.0 & 840.6 & 851.9 & 986.0 & 1304.3 & 1307.0 & 1549.6 \\
\hline $\begin{array}{c}\text { St. deviation } \\
\sigma_{\lambda}(\mathrm{nm})\end{array}$ & 0.09 & 0.30 & 0.21 & 0.24 & NA & 0.05 & 0.17 & 0.10 \\
\hline $\begin{array}{l}\text { Wavelength } \\
\text { uncertainty } \\
\left(0.125^{2}+\sigma_{\lambda}^{2}\right)^{1 / 2}\end{array}$ & 0.15 & 0.33 & 0.24 & 0.27 & NA & 0.14 & 0.21 & 0.16 \\
\hline
\end{tabular}




\section{Appendix E. Sample Results and Shipping Instructions for MAP}

This appendix describes MAP preliminary results and shipping instructions.

The following results are preliminary for the MAP power meter S/N 2946G04047 that was calibrated at $851.9,1307.0$, and $1549.6 \mathrm{~nm}$ using customer supplied single-mode fiber with FC connectors at both ends. The meter was set to 851.9, 1307.0, and $1549.6 \mathrm{~nm}$. Both Si detector (\#255) and Ge detector (\#133) were used. Si detector was used with laser wavelength of $851.9 \mathrm{~nm}$; $\mathrm{Ge}$ detector was used with laser wavelengths of 1307.0 and $1549.6 \mathrm{~nm}$. Time constant for Channel A was set to $200 \mathrm{~ms}$ for both detectors. The offset was set to $0 \mathrm{~dB}$. No lens was used.

Preliminary calibration factors using customer supplied fiber are as follows:

\subsection{8 for $851.9 \mathrm{~nm}$ laser source using Si detector. 1.018 for $1307.0 \mathrm{~mm}$ laser source using Ge detector. 1.004 for $1549.6 \mathrm{~nm}$ laser source using Ge detector.}

If the display or GPIB readings of the MAP meter are divided by these calibration factors, then the resulting values will coincide with the NIST national standard. Please, fill out 'Sample Data Sheet' for each of the wavelengths used and include any pertinent information for your standard.

More data will be collected after the instrument returns to NIST. We will submit a formal calibration report at that stage.

\section{SHIIPPING INSTRUCTIONS}

1. When you receive our transfer standard locate and read the enclosed operating instructions.

2. After completing the measurements, please, send the transfer standard and your measurement data to NIST (be sure to include the appropriate fiber cable(s), adapters, dust covers, etc.).

3. Ship to the following address:

\section{National Institute of Standards and Technology Attn: Igor Vayshenker/MS 815.01 (Rm.3082C) 325 Broadway Boulder, CO 80303}

4. Before shipping back to NIST, securely pack the instrument. Disconnect all the plug-in cables before shipping.

5. Insure the package for $\$ 10,000$. 


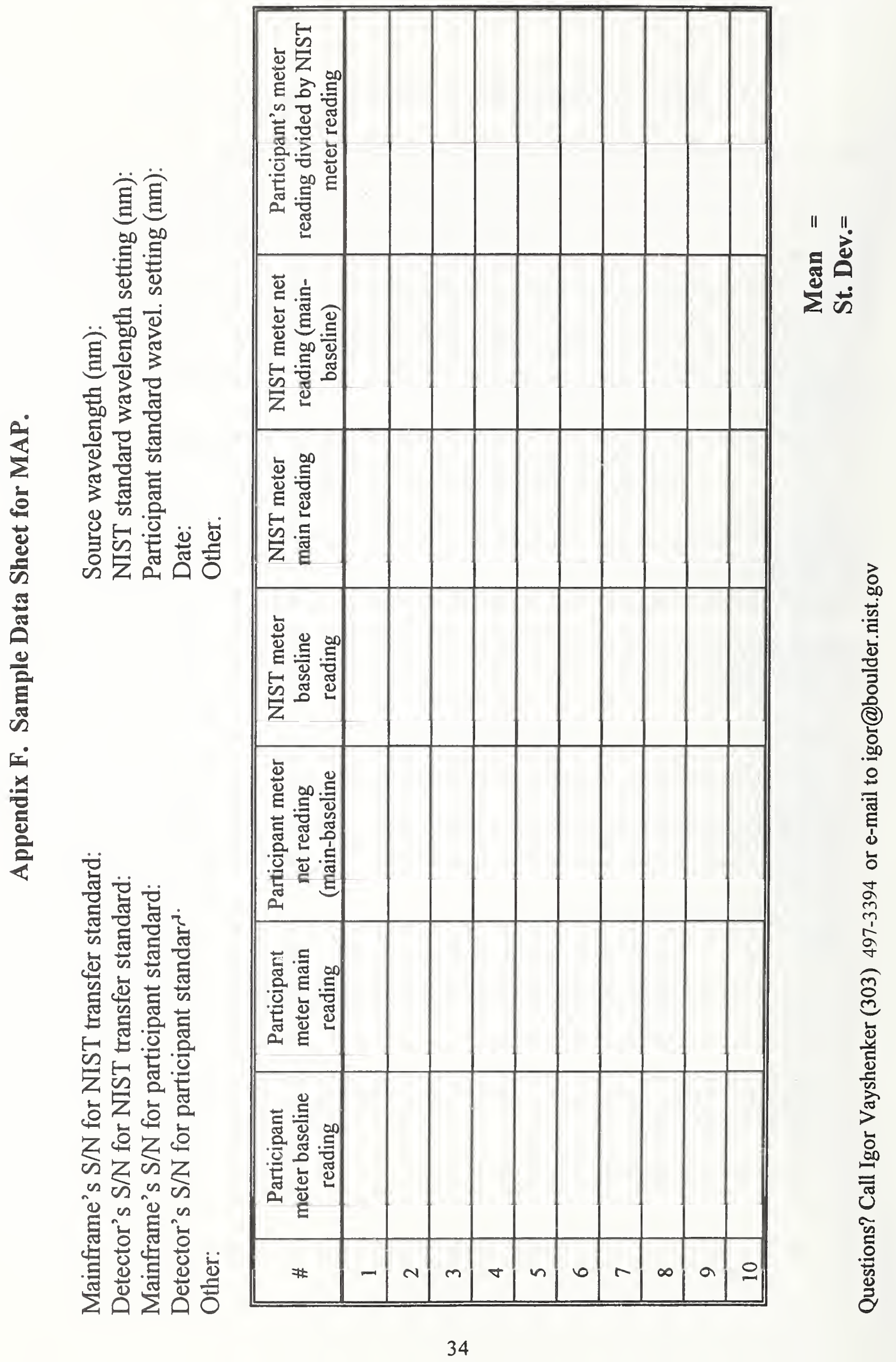


Appendix G. ECPR Linearity Measurements

Table G-1. ECPR \#483 calibrations against the LOCR at different powers.

\begin{tabular}{cccc}
\hline $\begin{array}{c}\text { Average } \\
\text { power } \\
(\mathrm{mW})\end{array}$ & $\begin{array}{c}\text { Calibration } \\
\text { factor } \\
\text { (reading/ } \mu \mathrm{W})\end{array}$ & $\mathrm{N}$ & $\begin{array}{c}\text { Standard } \\
\text { deviation } \\
(\%)\end{array}$ \\
\hline 1.002 & 0.9887 & 4 & 0.01 \\
0.502 & 0.9881 & 4 & 0.02 \\
0.101 & 0.9886 & 5 & 0.13 \\
\hline
\end{tabular}

The largest difference in calibration factors is between calibrations at 0.5 and $1.0 \mathrm{~mW}$. The difference is $0.061 \%$. The standard uncertainty is $0.061 /(2 \sqrt{3})=0.02 \%$. 


\section{Appendix H. ECPR Uniformity Scans}

ECPR uniformity measurements performed by D. Livigni on ECPR \#618 at a wavelength of 1557 nm.

Statistics for $2 \mathrm{~mm}$ beam with uniform centering error within $\pm 0.5 \mathrm{~mm}$ of true center: The standard deviation is $0.03 \%$.

The spread (between minimum and maximum) is $0.13 \%$.

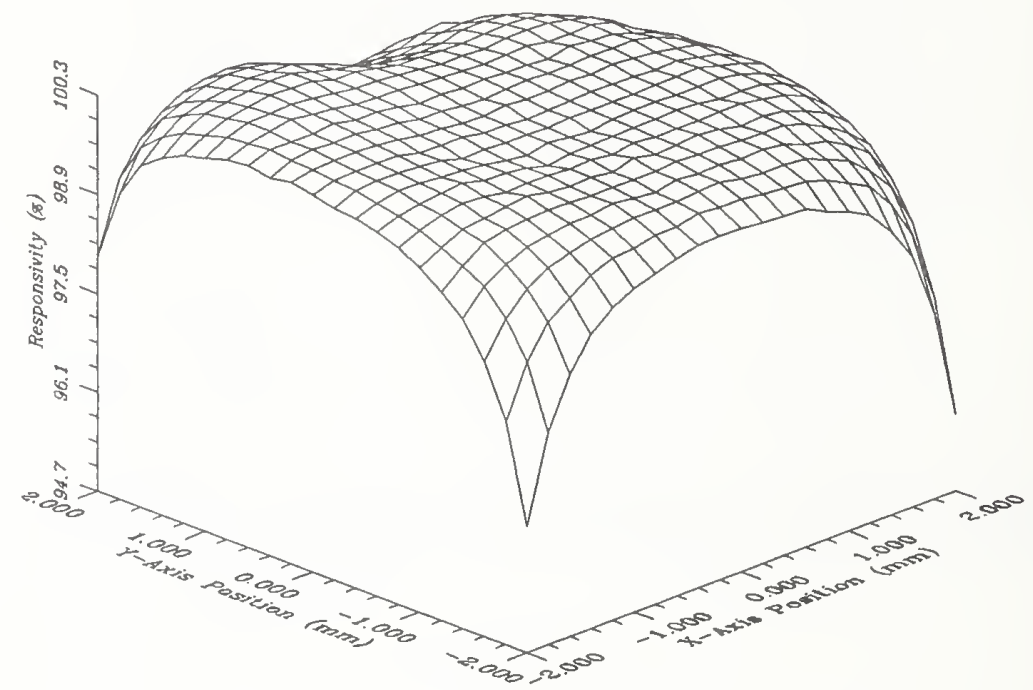

Figure 1. Surface plot of the entire dataset.

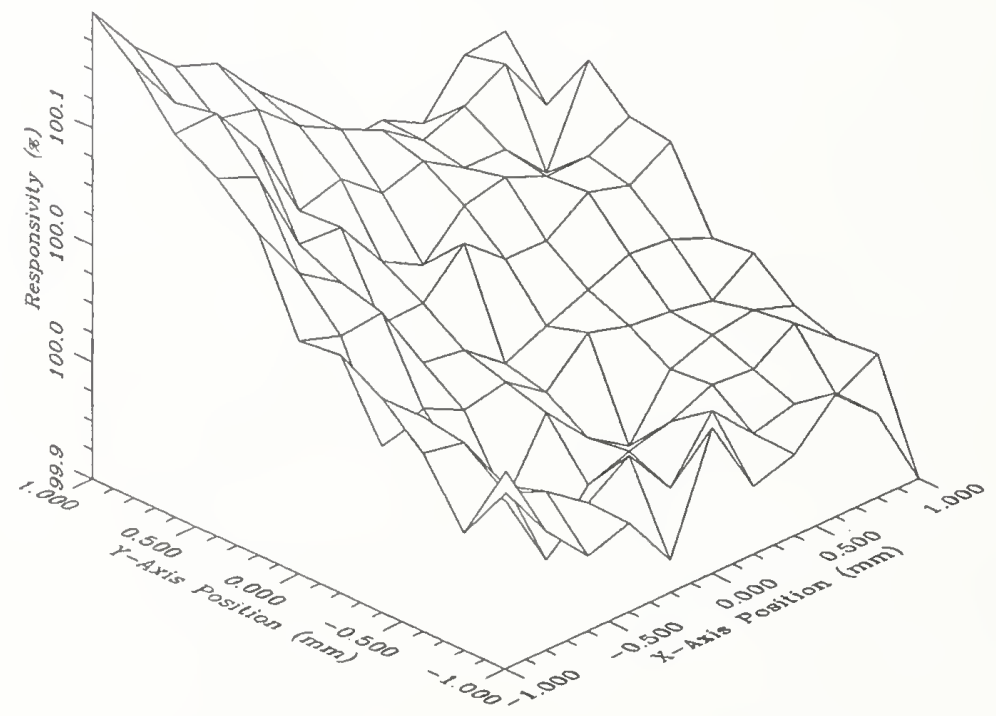

Figure 2. Surface plot around the detector's center. 
SP 250-1 Spectral Radiance Calibrations PB87179883

SP 250-2 Far Ultraviolet Detector Standards PB87227609

SP 250-3 Radiometric Standards in the Vacuum Ultraviolet PB87227625

SP 250-4 Fricke Dosimetry in High-Energy Electron Beams PB88110374

SP 250-5 Alpha-Particle Calibrations PB88168620

SP 250-6 Regular Spectral Transmittance PB88108550

SP 250-7 Radiance Temperature Calibrations PB88123674

SP 250-8 Spectral Reflectance PB88109905

SP 250-9 Calibration of Beta-Particle-Emitting Ophthalmic Applicators PB88108535

SP 250-10 Radioactivity Calibrations with the " $4 \pi$ " Gamma Ionization Chamber and Other Radioactivity Calibration Capabilities PB88123708

SP 250-11 Dosimetry for High Dose Applications PB88201587

SP 250-12 Neutron Personnel Dosimetry PB87227617

SP 250-13 Activation Foil Irradiation with Californium Fission Sources PB88217443

SP 250-14 Activation Foil Irradiation by Reactor Cavity Fission Sources PB88217435

SP 250-15 Photometric Calibrations PB88153747

SP 250-16 Calibration of X-Ray and Gamma-Ray Measuring Instruments PB88211826

SP 250-17 The NBS Photodetector Spectral Response Calibration Transfer Program PB88201595

SP 250-18 Neutron Source Strength Calibrations PB88211818

SP 250-19 Calibration of Gamma-Ray-Emitting Brachytherapy Sources PB89193858

SP 250-20 Spectral Irradiance Calibrations PB88123781

SP 250-21 Calibration of Beta-Particle Radiation Instrumentation PB88201579

SP 250-22 Platinum Resistance Thermometer Calibrations PB88138367

SP 250-23 Liquid-in-Glass Thermometer Calibration Service PB89128888

\author{
SP 250-24 Standard Cell Calibrations \\ PB88123690 \\ SP 250-25 Calibration Service for Inductive \\ Voltage Dividers \\ SP 250-26 NBS Phase Angle Calibration Services \\ PB88225636 \\ SP 250-27 AC-DC Difference Calibrations \\ PB892222616 \\ SP 250-28 Solid-State DC Voltage Standard Calibrations \\ PB88168703 \\ SP 250-29 Traceable Frequency Calibrations \\ PB88168364 \\ SP 250-30 GOES Satellite Time Code Dissemination: \\ Description and Operation \\ PB88168760 \\ SP 250-31 Mass Calibrations \\ PB89153894 \\ SP 250-32 A Calibration Service for $30 \mathrm{MHz}$ Attenuation \\ and Phase Shift \\ PB88238324
}

SP 250-33 A Calibration Service for Voltage Transformers and High-Voltage Capacitors PB882252903

SP 250-34 High Vacuum Standard and Its Use PB89193841

SP 250-35 The Calibration of Thermocouples and Thermocouple Materials PB89209340

SP 250-36 A Calibration Service for Current Transformers PB91216770

SP 250-37 Photometric Calibrations PB97148472

SP 250-38 NIST Leak Calibration Service PB92149772

SP 250-39 NIST Pressure Calibration Service PB94164043

SP 250-40 Absorbed-Dose Calibration of Ionization Chambers in a ${ }^{60} \mathrm{Co}$ Gamma-Ray Beam SN003-003-03034-1 \$2.00

SP 250-41 Spectroradiometric Detector Measurements: Part I - Ultraviolet Detectors and Part II - Visible to Near-Infrared Detectors SN003-003-03550-5 \$9.50

SP 250-42 Sprectroradiometric Detector Measurements: Part III-Infrared Detectors SN003-003-03582-3 \$5.25

SP 250-43 Radiance Temperature Calibrations SN003-003-03511-4 \$10.00

SP 250-44 Radiation Processing Dosimetry Calibration Services and Measurement Assurance Program SN003-003-03513-1

* Entries containing a stock number (SN003-003-) and price can be purchased from the Superintendent of Documents, U.S. Government Printing Office, Washington, DC 20402-9325. GPO will accept checks, money orders, VISA, and MasterCard. For more infomation, or to place an order, call (202) 512-1800. Be sure to cite the stock number on all orders.

Entries containing PB numbers can be purchased from the National Technical Information Service, Springfield, VA 22161. NTIS will accept American Express in addition to the payment methods listed for GPO. For more information call (703)487-4650; to place an order call (800) 553-6487. Fax: (703) 321-8547. Be sure to cite the PB number on all orders.

Entries without stock or PB numbers are in preparation. 
SP 250-45 Radiation Processing Dosimetry Calibration Services: Manual of Calibration Procedures SN003-003-03514-9 \$4.00

SP 250-46 NIST Multifunction Calibration System SN003-003-03515-7 \$2.75

SP 250-47 NIST Calibration Service for Capacitance Standards at Low Frequencies SN003-003-03549-1 $\$ 7.00$

SP 250-48 Spectral Reflectance SN003-003-03545-9 $\$ 14.00$

SP 250-49 NIST Calibration Services for Gas Flow Meters: Piston Prover and Bell Prover Gas Flow Facilities SN003-003-03560-2 \$6.00

SP 250-51 Calibration Service of Optoelectronic Frequency Response at $1319 \mathrm{~nm}$ for Combined Photodiode/rf Power Sensor Transfer Standards SN003-003-03623-4

SP 250-52 Error Analysis and Calibration Uncertainty of Capacitance Standards at NIST

SP 250-53 Calibration Service for Spectral Responsivity of Laser and Optical-Fiber Power Meters at Wavelengths Between $0.4 \mu \mathrm{m}$ and $1.8 \mu \mathrm{m}$ SN003-003 03624-2

SP 250-54 Optical Fiber Power Meter Calibrations at NIST

SP 250-56 Optical Fiber Power Meter Nonlinearity Calibrations at NIST

* Entries containing a stock number (SN003-003-) and price can be purchased from the Superintendent of Documents, U.S. Government Printing Office, Washington, DC 20402-9325. GPO will accept checks, money orders, VISA, and MasterCard. For more infomation, or to place an order, call (202) 512-1800. Be sure to cite the stock number on all orders.

Entries containing PB numbers can be purchased from the National Technical Information Service, Springfield, VA 22161. NTIS will accept American Express in addition to the payment methods listed for GPO. For more information call (703)487-4650; to place an order call (800) 553-6487. Fax: (703) 321-8547. Be sure to cite the PB number on all orders.

Entries without stock or PB numbers are in preparation. 



\section{.}




\section{Technical Publications}

\section{Periodical}

Journal of Research of the National Institute of Standards and Technology-Reports NIST research and development in those disciplines of the physical and engineering sciences in which the Institute is active. These include physics, chemistry, engineering, mathematics, and computer sciences. Papers cover a broad range of subjects, with major emphasis on measurement methodology and the basic technology underlying standardization. Also included from time to time are survey articles on topics closely related to the Institute's technical and scientific programs. Issued six times a year.

\section{Nonperiodicals}

Monographs-Major contributions to the technical literature on various subjects related to the Institute's scientific and technical activities.

Handbooks-Recommended codes of engineering and industrial practice (including safety codes) developed in cooperation with interested industries, professional organizations, and regulatory bodies.

Special Publications-Include proceedings of conferences sponsored by NIST, NIST annual reports, and other special publications appropriate to this grouping such as wall charts, pocket cards, and bibliographies.

National Standard Reference Data Series-Provides quantitative data on the physical and chemical properties of materials, compiled from the world's literature and critically evaluated. Developed under a worldwide program coordinated by NIST under the authority of the National Standard Data Act (Public Law 90-396). NOTE: The Journal of Physical and Chemical Reference Data (JPCRD) is published bi-monthly for NIST by the American Chemical Society (ACS) and the American Institute of Physics (AIP). Subscriptions, reprints, and supplements are available from ACS, 1155 Sixteenth St., NW, Washington, DC 20056.

Building Science Series-Disseminates technical information developed at the Institute on building materials, components, systems, and whole structures. The series presents research results, test methods, and performance criteria related to the structural and environmental functions and the durability and safety characteristics of building elements and systems.

Technical Notes-Studies or reports which are complete in themselves but restrictive in their treatment of a subject. Analogous to monographs but not so comprehensive in scope or definitive in treatment of the subject area. Often serve as a vehicle for final reports of work performed at NIST under the sponsorship of other government agencies.

Voluntary Product Standards-Developed under procedures published by the Department of Commerce in Part 10, Title 15, of the Code of Federal Regulations. The standards establish nationally recognized requirements for products, and provide all concerned interests with a basis for common understanding of the characteristics of the products. NIST administers this program in support of the efforts of private-sector standardizing organizations.

Order the following NIST publications_FIPS and NISTIRs-from the National Technical Information Service, Springfield, VA 22161.

Federal Information Processing Standards Publications (FIPS PUB)—Publications in this series collectively constitute the Federal Information Processing Standards Register. The Register serves as the official source of information in the Federal Government regarding standards issued by NIST pursuant to the Federal Property and Administrative Services Act of 1949 as amended, Public Law 89-306 (79 Stat. 1127), and as implemented by Executive Order 11717 (38 FR 12315, dated May 11, 1973) and Part 6 of Title 15 CFR (Code of Federal Regulations).

NIST Interagency Reports (NISTIR)-A special series of interim or final reports on work performed by NIST for outside sponsors (both government and nongovernment). In general, initial distribution is handled by the sponsor; public distribution is by the National Technical Information Service, Springfield, VA 22161, in paper copy or microfiche form. 


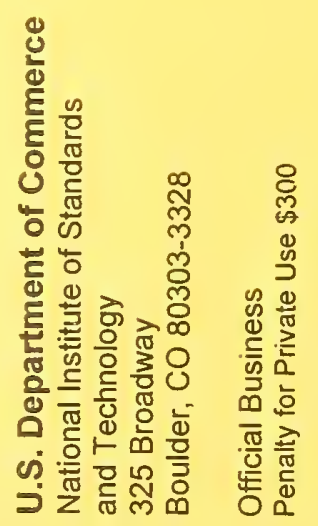

